\title{
1 Soil and water conservation measures reduce 2 soil and water losses in China but not down 3 to background levels: evidence from erosion 4 plot data
}

6 Jianlin Zhao ${ }^{1,2,3,4}$, Zhiqiang Yang ${ }^{1,2,3}$, Gerard Govers ${ }^{4}$

7 1. Department of Geology Engineering and Geomatics, Chang'an University,

8 Yantalu 120, Xi'an 710054, China.

9 2. National administration of surveying, mapping and geoinformation, Engineering

10 research center of national geographic conditions monitoring, Xi' an, 710054, 11 China.

12 3. Key Laboratory of Western China's Mineral Resources and Geological 13 Engineering, Ministry of Education, Xi' an 710054, China.

14 4. Division of Geography, Department of Earth and Environmental Sciences, KU 15 Leuven, Leuven 3000, Belgium.

16 Corresponding: jianlin.zhao@hotmail.com. 


\section{Abstract}

18 The efficacy of soil and water conservation measures (SWCMs) on reducing the

19 loss of soil and water have been widely tested at the plot scale in China. However,

20 an integrated comparison of the efficacy and an overall investigation of the

21 controlling factors of the efficacy is absent. Therefore, an extensive dataset

22 compiling erosion plot measurement of applying SWCMs on controlling soil loss

23 and runoff in China was established in this study. In total, 848 erosion plots

24 representing 2494 plot years were retained in this dataset which compiled from

25108 publications and 2 data reports. The 15 most frequently tested SWCMs were

26 identified and described. Soil loss ratio $(S L R)$ and runoff ratio $(R R)$ of each SWCMs

27 was calculated to assess the efficacy of an SWCMs on reducing soil and water

28 loss. The potential controlling factors, such as slope, slope length, annual

29 precipitation, were evaluated for the controlling factor for both $S L R$ and $R R$. Our

30 results suggested that in general, applying the SWCMs can reduce soil loss by ca.

$3170 \%$ (overall $S L R$ is $0.39 \pm 0.02$ ) and runoff by ca. $50 \%$ (overall $R R$ is $0.54 \pm 0.05$ ),

32 respectively. However, erosion rates on plots with SWCMs in China were, in

33 general, still significantly higher than erosion rates measured under permanent

34 vegetation cover land and, on average, ca. one order of magnitude higher than soil

35 formation rates which required for a soil-neutral agriculture. On overall, the $S L R$

36 presented a significant relation with topographic factors: positive with slope

37 gradient and negative with slope length. This suggests that the support practice

38 factor ( $P$ factor) of RUSLE model might be overestimated when values measured

39 from plot scale are directly applied to larger areas (catchment or region scale). The 
$40 S L R$ and $R R$ values presented in this study can be applied for the planning of

41 SWCMs in China and can be used to estimate the $P$ factor when applying RUSLE

42 model whereby the effect of topographic factors on SWCM efficacy can be

43 accounted for.

44 Keywords: soil and water conservation measures; soil loss ratio; runoff ratio;

45 controlling factors; soil formation rates.

\section{1. Introduction}

47 Soil erosion is a widely spread environmental problem (Lal, 2003). Globally, ca.

$48 \quad 22-35$ Gt of soil is annually mobilized by water and tillage erosion on agricultural

49 land (Govers et al., 2013; Van Oost et al., 2007). Severe soil erosion not only

50 threatens the sustainability of agriculture by reducing the soil's water holding

51 capacity and its nutrient and soil organic carbon content (Bakker et al., 2004;

52 Quinton et al., 2010; Zhao et al., 2016a) but also causes off-site reservoir siltation

53 and water pollution (Lal, 1998). Also in China, water erosion is widely occurring

54 and is acknowledged as a serious problem in many agricultural areas. Erosion

55 rates exceeding $100 \mathrm{t} \mathrm{ha}^{-1} \mathrm{yr}^{-1}$ have been reported on the Chinese loess plateau

56 (Li et al., 2015; Shi and Shao, 2000; Yang et al., 2006; Zhao et al., 2016b) while

57 erosion rates can exceed $50 \mathrm{t} \mathrm{ha}^{-1} \mathrm{yr}^{-1}$ in the south and southwest of China (Lu et

58 al., 2004; Zhang et al., 2004, 2003).

59 A range of soil conservation technologies is now applied around the world to

60 combat the loss of soil and water, including conservation tillage, terracing,

61 hedgerow planting and mulching (Maetens et al., 2012; Mason et al., 2015; 
62 Prosdocimi et al., 2016; Taye et al., 2013). Soil and water conservation measures

63 (SWCMs) can be effectively used to reduce and control soil erosion and sediment

64 mobilization (Maetens et al., 2012; Montgomery, 2007). Since antiquity (ca. 5000

65 BP) terracing was used to protect the soil in China (Wei et al., 2016). Since ca.

661960 , other SWCMs are also being used and the rate of implementation of soil

67 conservation measures has accelerated: Liu et al. (2013) identified 53 different

68 types of SWCMs that are being tested and applied in China. Some of these

69 techniques are nowadays widely applied: for instance, ca. $50 \%$ of the arable land

70 with a slope gradient $>5 \%$ on the Chinese Loess Plateau has now been terraced

71 (Zhao et al., 2016a)

72 As is the case elsewhere, the efficacy of soil conservation measures in China was

73 tested by establishing paired erosion plot experiments. Soil loss and runoff rate on

74 one or more erosion plots where SWCMs were applied was compared with the soil

75 loss and runoff rate on one or more conventional erosion plots without SWCMs.

76 Several of such experimental studies were conducted in different agro-ecological

77 settings and testing different soil conservation techniques (Cai, 2004; Xu et al.,

78 2010; Zhou et al., 2011). The measured soil loss $(S L R)$ and runoff $(R R)$ ratios, i.e.

79 the ratio of soil loss and runoff of SWCMs plot to the reference ( or conventional

80 agricultural management) plot with same environmental condition except for the

81 application of an SWCMs, can then be used as an index for assessing for the

82 efficacy of SWCMs (Maetens et al., 2012).

83 While individual experimental studies do provide important information, they do not

84 always allow to gain a full understanding of the efficacy of SWCMs. Erosion is 
85 known to be highly variable in both space and time and the same is true when the 86 efficacy of SWCMs is considered (Leys et al., 2010; Maetens et al., 2012). Thus, 87 the efficacy of a particular SWCMs as measured in a single study is inevitably 88 subject to a large uncertainty. Furthermore, land managers should have 89 information on the efficacy of different SWCMs when making a choice, taking also 90 into account other important factors such as cost and social acceptability while 91 most empirical studies only test a single SWCM. Evaluating and comparing the 92 performance of different SWCMs while considering uncertainty is only possible 93 when the results of individual experimental studies are combined in meta-analysis.

94 Gaining insight into the overall efficacy of SWCMs also allows gaining insight into 95 the degree to which soil conservation measures do indeed effectively protect the 96 soil resource. It is well known that, when correctly implemented, SWCMs can 97 considerably reduce soil erosion and runoff from plot to catchment scales (Fu et 98 al., 2005; Maetens et al., 2012). Montgomery (2007), using main data from the 99 United States, reported that soil erosion rates, which are strongly accelerated by 100 conventional agricultural activities, can be reduced to values close to the 101 background erosion rates by using conservation tillage. This implies that 102 conservation tillage allows to re-instate an equilibrium between soil production and 103 soil loss. However, this conclusion may not be universally valid: variations in crops, 104 climate, topography and soil type may affect the efficacy of conservation tillage 105 and other SWCMs. Quantifying and understanding this variability will allow to 106 evaluate under what conditions SWCMs are indeed effective in protecting 107 agricultural land from further degradation. 
108 A comprehensive study to assess the efficacy of SWCMs in China is, at present,

109 absent. While valuable information may be derived from existing meta-analyses of

110 SWCMs, the results of these studies cannot directly be applied to China. First,

111 environmental conditions in China are different from those in the North America or

112 Europe where earlier meta-studies were carried out: in comparison to these

113 regions, arable land plots in China is located on much steeper slopes and rainfall

114 erosivity is, in general, high (Fig.2; Panagos et al., 2015; Qin et al., 2016). Second,

115 some soil conservation technologies that are being used in China are not being

116 applied elsewhere in the world (Table 1).

117 In this study, we compiled a relatively extensive erosion plot database of erosion

118 plot studies carried out in China in which the soil loss ratio and runoff ratio for one

119 or several SWCMs was assessed under field conditions. Based on this database,

120 the overall efficacy of these SWCMs was analysed. We also explored the effect of

121 environmental factors such as climate and topography on the efficacy of SWCMs.

122 Finally, we compared the reduction in soil loss with literature information on soil

123 formation rate (similar to Montgomery, 2007) so that we can assess to what extent

124 soils in China can effectively be protected against erosion by soil and water

125 conservation technology

\section{2. Materials and Methods}

\section{2.1. Erosion plot database}

128 Data on plot experiments wherein the annual soil loss rate $\left(S L, \mathrm{tha}^{-1} \mathrm{yr}^{-1}\right)$ and

129 annual runoff rate $\left(R, \mathrm{~mm} \mathrm{yr}^{-1}\right)$ as on erosion plots under natural rainfall in China 
130 with and without SWCMs were compared were collected from the literature. The

131 main sources of information were peer-reviewed papers and so-called hydro-

132 station reports about SWCMs experiments. The hydro-station reports were

133 obtained from the National Data Sharing Infrastructure of Earth System Science,

134 China (http://www2.geodata.cn/) which reported measured soil loss and runoff

135 rates for erosion plots from 12 hydro-stations all located in Shaanxi provinces of

136 China where experiments were carried out, mostly in the 1960s and 1970s. For

137 each plot, the following information was entered in the database, if available:

138 location, measurement methods, measurement period (year), land use, slope

139 gradient ( $S$, degree), slope length ( $L$, meter), the SWCM applied, annual

140 precipitation $(P, \mathrm{~mm})$, runoff rate $\left(R, \mathrm{~mm} \mathrm{yr}^{-1}\right)$, runoff coefficient $(R C, \%)$ and soil

141 loss rate $\left(S L, \mathrm{t} \mathrm{ha}^{-1} \mathrm{yr}^{-1}\right)$. We only retained studies where soil loss and runoff were

142 measured during at least one full year. Most data come from paired erosion plot

143 studies, which were set up to assess the efficacy of a SWCMs for reducing soil

144 loss and/or runoff by comparing one or more plots under conventional

145 management with one or more plots under conservation management. Data from

146 these studies were used to make a direct comparison between conventional and

147 conservation management through the calculation of soil loss and runoff ratios.

148 The data from studies wherein no paired plot design was used were only used to

149 assess the overall efficacy of an SWCM by calculating the soil loss rate for that

150 particular SWCM. If plots were replicated, the number of plots $(P N)$ equals the

151 number of replicates while the number of plot years $(P Y)$ equals the number of

152 plots multiplied by the number of years that observations were carried out. Thus, 
153 one $P Y$ represents an observation period of one year of soil loss/runoff on a single

154 erosion plot (Maetens et al., 2012).

\section{2.2. The soil and water conservation plots database}

156 In total, data from 848 erosion plots representing 2494 plot years were compiled

157 in this study from 108 publications and two hydro-station reports. On 644 of the

158 plots, representing $1858 \mathrm{PY}$, one of more SWCMs were applied while 204 erosion

159 plots representing $636 P Y$ were under conventional agriculture. Most plots with

160 SWCMS (452, representing 1345 PY) were in paired plot experiments while 192

161 (representing 513 PY) were not. Erosion plots were distributed over 117 sites or

162 stations which covered most regions of China (Fig. 1). Most erosion plots were

163 located in the east of China where soil erosion by water is known to be important.

164 About $74 \%$ of those erosion plots was under arable land use $(P N=627, P Y=$

165 1980), 11\% was under permanent vegetation cover (forest and shrub, $P N=94$,

$166 P Y=297), 9 \%$ was under barren land $(P N=78, P Y=103)$ and $5 \%$ was under

167 grassland $(P N=44, P Y=100)$. Only 5 plots $(P Y=14)$ were under fallow. Erosion

168 plots established under permanent vegetation cover were usually established to 169 assess the efficacy of conservation techniques during land preparation for

170 reforestation. The frequency distribution of plots with respect to the slope gradient

171 (Fig. 2a) showed that the erosion plots in China were constructed on relatively

172 steep slopes (mean: 15.0 degrees, SD: 8.1 degrees, $n=848$ ) in comparison to the

173 "standard RUSLE erosion plots" in the US, which have a slope gradient of 5.1

174 degrees or $9.0 \%$ (Renard et al., 1997). The slope length (mean: 18.9 meter, SD: 
1756.8 meter, $n=848$ ) in our erosion plots was close to the standard slope length 176 (22.13 meter) of standard RUSLE plots (Fig. 2b).

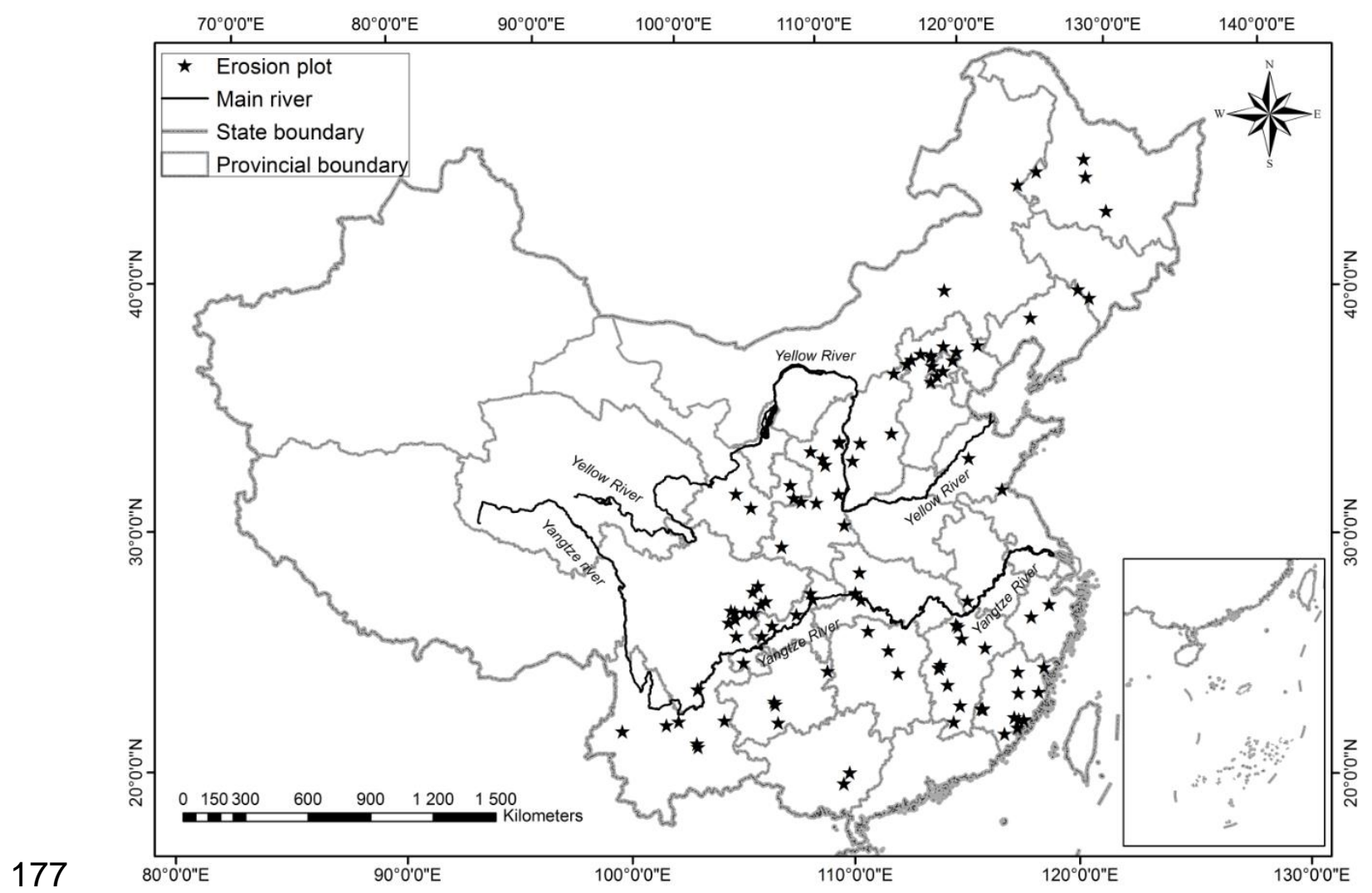

178

Fig.1 Location of erosion plots. 

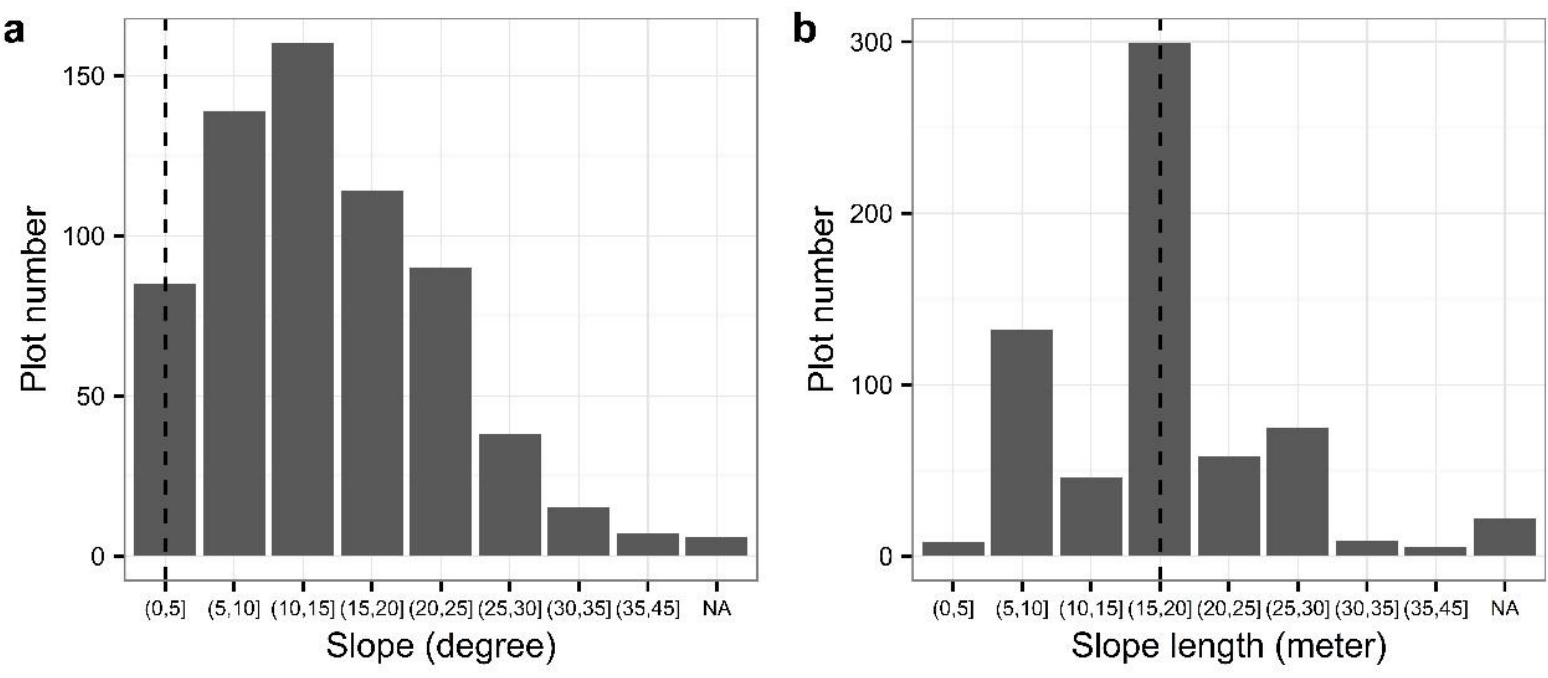

180 Fig.2 Frequency distribution of the $S(\mathrm{a})$ and $L$ (b) of erosion plots. The dashed line is the 181 standard $S$ (5.1 degrees or $9 \%$ ) (a) and $L$ (22.13 meter) (b) of RUSLE erosion plots (Renard 182 et al., 1997).

\section{2.3. Soil and water conservation measures in China}

184 According to the terminology introduced by the national standards of soil and water 185 conservation (GB/T 20465-2006, Liu et al. (2013)), soil and water conservation

186 measures are divided into 3 major categories in China. These categories are (i) 187 engineering measures (EM), (ii) vegetation measures (VM) and (iii) agricultural 188 measures $(A M)$. In total $39 \mathrm{EM}, 13 \mathrm{VM}$ and $8 A M$ of soil and water conservation 189 measures were defined in China (Liu et al., 2013). The 15 soil and water 190 conservation measures that were most frequently tested (i.e. on at least 3 plots 191 according to our data) are described in Table 1.

192 Contour tillage and no-tillage were the most widely tested agricultural measures 193 while level terracing was the most frequently applied engineering measure. The 194 planting of hedgerows was by far the most frequently applied vegetation measure 195 (Table 1). 
196 Table 1 Definition of most frequently used SWCMs in China: $P N$ is the number of plots 197 and $P Y$ is the number of plot years.

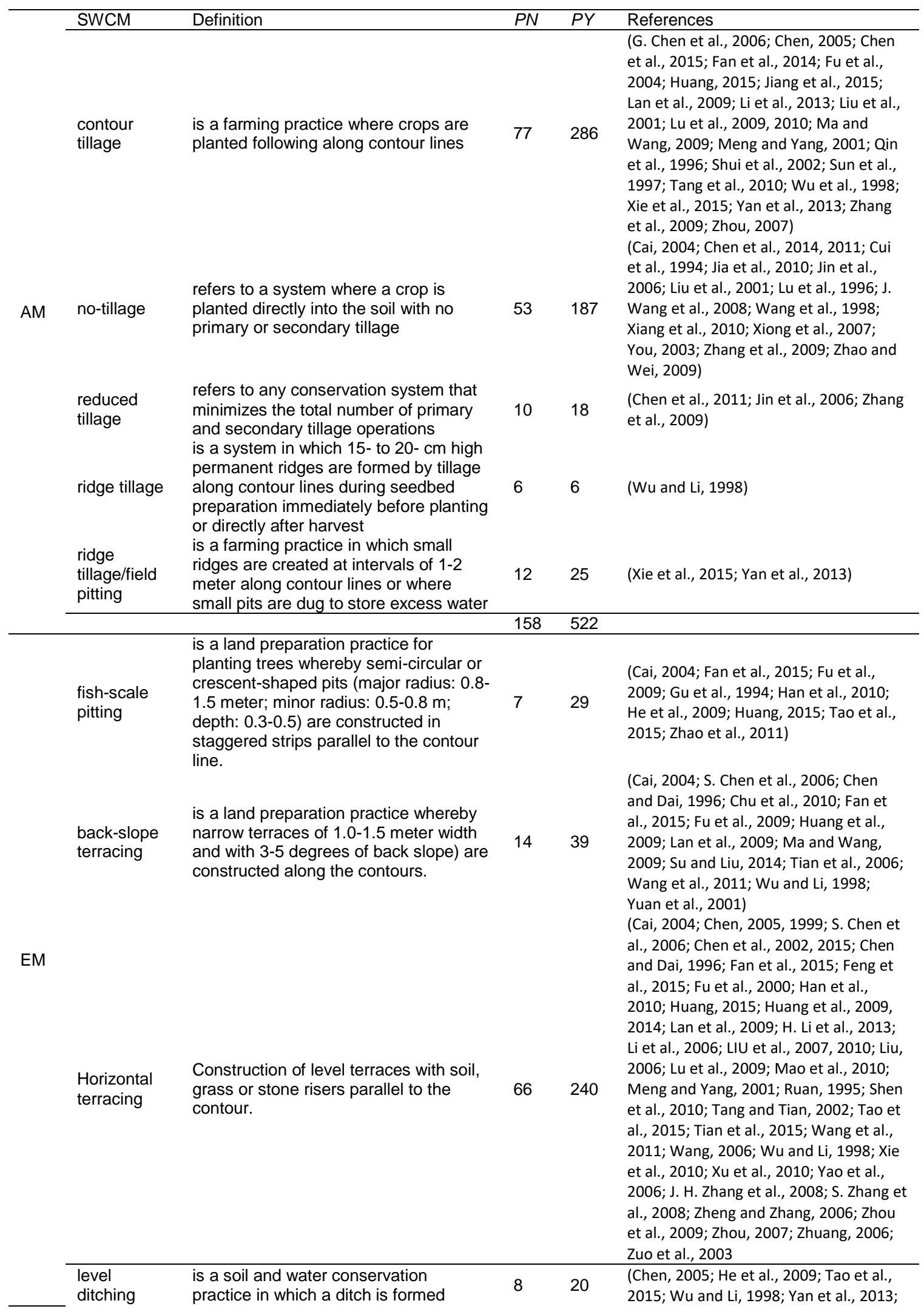


along the contour line to trap runoff and drainage runoff in the field slope

is a surface cover measure whereby grass is planted between or into the main crop. The grass is planted either in full cover or in strip cover to protect soil from erosion

is a vegetation measure whereby strips of perennial vegetation (shrub or grass) hedgerows are planted along the contour line of the slope to intercept runoff and control soil loss.

VM intercroppin g

Mulching

Natural restoration

strip two crops or one crop and grassland intercroppin are grown simultaneously on the same g is a multiple cropping system where two or more crops are planted is a surface cover measure which leaves a mulch, such as vegetation residues, biological geotextiles or rock fragments on the soil surface for soil and water conservation.

A technique whereby the vegetation degraded land is restored by creating enclosures from which livestock is excluded

Strip intercropping is a system where field in alternating strips parallel to the contour simultaneously on the same field.
Yin et al., 2001; Yuan et al., 2001; Yue, 2008; Zheng et al., 2012)

97 334 (Huang et al., 2007; Jiang and Shao, 2011; Liu, 2007, 2006; Tang and Tian, 48164 2002; J. Wang et al., 2008; Wang et al., 2011; Wang, 2006; Xie et al., 2010; Yang et al., 2012; Zi et al., 2006)

(Chen et al., 2002; S. Chen et al., 2006; Chen et al., 2015; Huang et al., 2012, 2009; Jiang et al., 2015; Lan et al., 2009; Lin et al., 2007; Lu et al., 2009; Mao et al., 2010; Mi et al., 2006; Ng et al., 2008; 108226 Ruan, 1995; Shen et al., 2010; Sun et al., 1999; Tang et al., 2010; J. Wang et al., 2008; Xu et al., 2010; Yan et al., 2013; Yin et al., 2001; Yu et al., 2010; Yuan et al., 2001; Zhang et al., 2011; Zheng et al., 2012; Zhou, 2007)

(Fu et al., 2000; Wu and Li, 1998; Xie et al., 2010)

(Jiang and Shao, 2011; X. Wang et al., 2008; Xue et al., 2011)

(G. Chen et al., 2006; He et al., 2009; Lan et al., 2009; Tian et al., 2006; X. Wang et al., 2008)

15

(Wu and Li, 1998)

199 The $S L R$ and $R R$ were calculated as follows (Maetens et al., 2012):

$$
S L R=\frac{S L_{S W C M S}}{S L_{C O N V}}
$$

$$
R R=\frac{R_{\text {SWCMS }}}{R_{C O N V}}
$$

202 Where, SLSWCMS and $R_{\text {SWCMS }}$ are respectively the soil loss (t ha- $\left.\mathrm{yr}^{-1}\right)$ and runoff 203 rate $\left(\mathrm{mm} \mathrm{yr}^{-1}\right)$ of the erosion plot under SWCMs; while $S L_{\text {CONV }}$ and $R$ CoNv are 204 respectively the soil loss $\left(\mathrm{t} \mathrm{ha}^{-1} \mathrm{yr}^{-1}\right)$ and runoff $\left(\mathrm{mm} \mathrm{yr}^{-1}\right)$ rate of corresponding 
205 erosion plots under conventional management (or reference plot) which had same 206 plot characteristic as the SWCMs plot but without the application of SWCM. Thus, 207 higher SLR and $R R$ values indicate a lower efficacy of SWCMs.

\section{$208 \quad 2.5$. Statistical analysis}

209 We investigated the relation between $S L R$ and $R R$ on the one hand and average 210 annual precipitation $(P)$ at the plot site, slope length $(L)$, slope gradient $(S)$, as well 211 as absolute values of soil loss $(S L)$ and runoff $(R)$ on the other hand. We did not 212 only consider the overall variation of $S L R$ and $R R$ over all plots (thus including all 213 SWCMs), but also the variation for the five most widely tested SWCMs: level 214 terracing, contour tillage, grass cover, no-tillage and hedgerow (Table 1).

215 We used non-parametric tests as well as (weighted) linear regression in statistical 216 analysis. Observations were weighted by the square root of the number of plot 217 years. Furthermore, the natural log value of both $S L R$ and $R R$ and the controlling 218 factors was used to account for the right-skewed nature of the distribution of 219 erosion and runoff rates, resulting in the following basic equation:

$$
\ln (Y)=a+b \ln (X)
$$

221 where, $Y$ is the value of $S L R$ or $R R$ and $X$ is the potential controlling factor (SL, $222 R, S$ and $L)$.

223 We calculated the coefficients ( $a$ and $b)$, the level of significance value $(p)$ and the 224 proportion of variance of $Y$ explained. We also combined all potential explanatory 
225 variables to predict $S L R$ and $R R$ using stepwise linear regression. All statistical 226 analyses were conducted using the R platform and R studio (Rstudio Team, 2015).

227 Evidently, we were limited by the data reported in the studies and not all relevant 228 factors could be investigated. Clearly factors, other than those evaluated here 229 (such as soil properties) may also affect the efficacy of SWCMs.

\section{3. Results}

\section{3.1. Overall efficacy of SWCMs in China}

232 On average, the soil loss rate on conventional erosion plots $\left(28.63 \pm 3.42 \mathrm{t} \mathrm{ha}^{-1} \mathrm{yr}^{-}\right.$ $\left.233{ }^{1}, \mathrm{n}=155\right)$ was ca. 3.5 times larger than the rate of soil loss under SWCMs $(8.63 \pm$ $2340.89 \mathrm{t} \mathrm{ha}^{-1} \mathrm{yr}^{-1}, \mathrm{n}=499$ ), which suggested that the implementation of SWCMs, on 235 overall average, reduced soil loss in China by ca. 70\%. The average weighted $S L R$ 236 for all pair's SWCMs plots suggests a somewhat lower efficacy than the direct 237 comparison of absolute soil erosion rates $(0.39 \pm 0.02(n=323))$. However, the 238 variation in efficacy within each group of conservation measures is very high, with 239 SLR's varying from $<0.05$ to $>2$ (Fig. 4).

240 Similarly, the comparison of annual runoff rates on SWCMs plots with runoff rates

241 under conventional agriculture indicated that SWCMs was able to successfully 242 reduce the runoff volume. The weighted mean annual runoff under conventional 243 management was $113.77 \pm 12.43 \mathrm{~mm} \mathrm{yr}^{-1}(\mathrm{n}=123)$ which was ca. 2 times larger 244 than that on plots under SWCMs $\left(54.53 \pm 4.10 \mathrm{~mm} \mathrm{yr}^{-1}, \mathrm{n}=383\right)$. The overall 245 weighted RR for all pair's plots is $0.54 \pm 0.05(n=263)$. 
246 The result of Wilcoxon two-samples nonparametric comparison indicated that 247 vegetation measures ( $V M)$ and engineering measures (EM) plots were, on average, 248 more efficient in comparison to agricultural measures $(A M)$ in reducing soil loss, 249 while engineering measures were significantly more effective in reducing runoff 250 than $A M$ and $V M$ (Table 2 and Fig. 3). The weighted mean SLR under $V M$ was $2510.31 \pm 0.03(P N=186, P Y=441)$ which was only slightly lower than the average 252 value under $E M(S L R=0.34 \pm 0.05, P N=97, P Y=334)$ but $A M$ were, on average, 253 far less, effective ( $S L R=0.51 \pm 0.03, P N=133, P Y=428)$. $E M$ reduced runoff, on 254 average, slightly more $(R R=0.41 \pm 0.03, P N=70, P Y=227)$ than $V M(R R=0.51$ $255 \pm 0.08, P N=145, P Y=335)$. The mean $R R$ for $A M$ was, on the other hand clearly 256 higher: $0.68 \pm 0.08(P N=124, P Y=314)$.

257 Table 2 Wilcoxon two-sample nonparametric comparison of $S L R$ and $R R$ among $A M, E M$ 258 and $V M$. Average and standard deviation as calculated for two groups of conservation 259 measures are given on each row. When values are given in bold they were significantly 260 different at the 0.05 level

\begin{tabular}{lll}
\hline & $S L R$ & $R R$ \\
\hline $\mathrm{AM}(E M)$ & $\mathbf{0 . 5 1} \pm \mathbf{0 . 0 3 ( 0 . 3 4 \pm 0 . 0 5 )}$ & $\mathbf{0 . 6 8} \pm 0.08(0.41 \pm 0.03)$ \\
$\mathrm{AM}(V M)$ & $\mathbf{0 . 5 1 \pm 0 . 0 3 ( 0 . 3 1 \pm 0 . 0 3 )}$ & $0.68 \pm 0.08(0.51 \pm 0.03)$ \\
$\mathrm{EM}(V M)$ & $0.34 \pm 0.05(0.31 \pm 0.03)$ & $\mathbf{0 . 4 1} \pm 0.03(0.51 \pm 0.08)$ \\
\hline
\end{tabular}



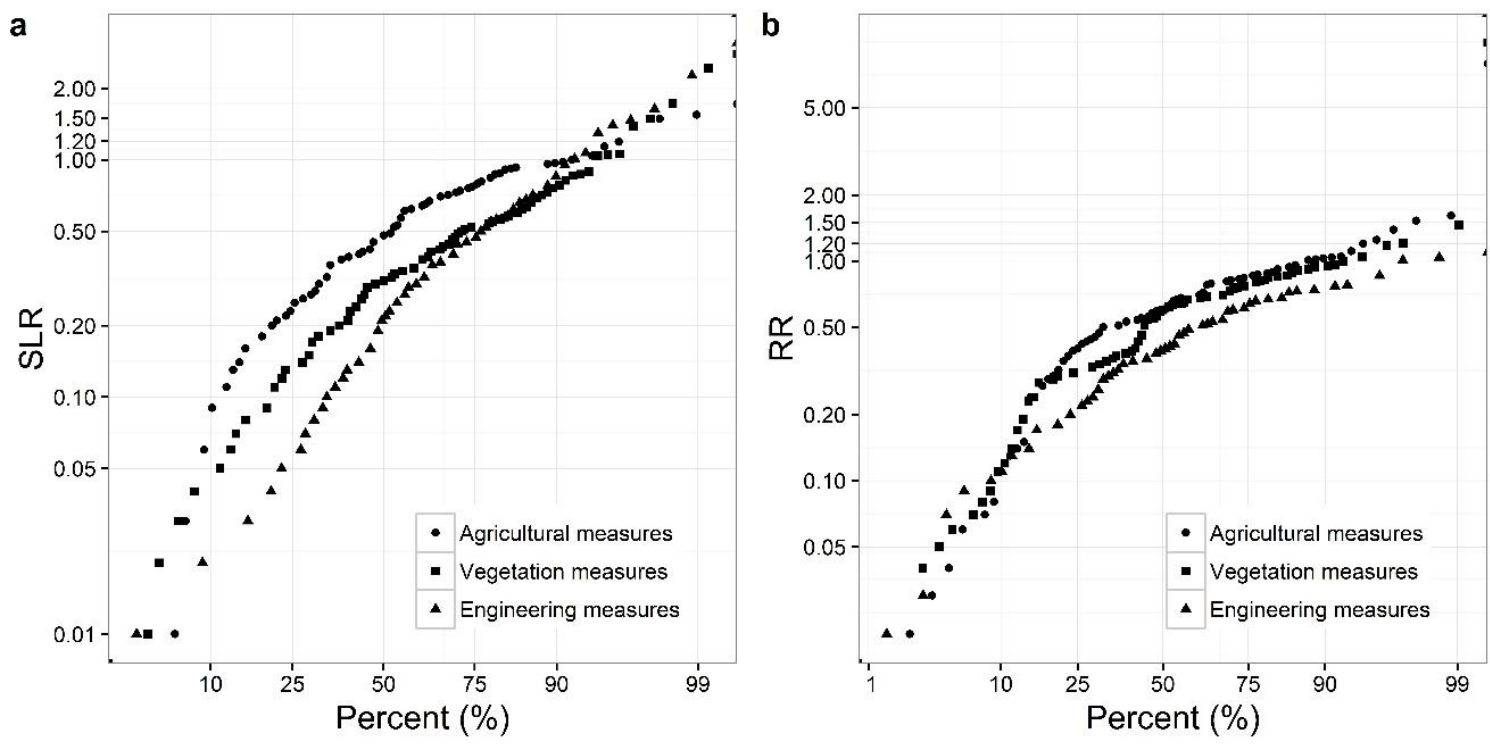

Fig. 3 Empirical cumulative distributions plots of the efficacy of SWCMs for soil loss and runoff.

\section{3.2. Soil conservation efficacy of different SWCMs}

265 The average SLR and RR for each SWCMs was summarized in Table 3 and Fig.4.

266 When SWCMs are considered separately, the most effective conservation

267 measure in reducing soil loss in China is grass cover with an average SLR of ca.

$2680.15 \pm 0.03(P N=48, P Y=164)$. Mulching $(P N=4, P Y=9)$ presented a similar

$269 S L R$ as grass cover with an average $S L R$ of $0.18 \pm 0.14$ but the number of

270 observations for mulching is too low to allow for robust conclusions. Horizontal

271 terracing, which is the most tested and widely used conservation measure in China

$272(P N=66, P Y=240)$, allowed to reduce erosion by ca. $67 \%$ ( $S L R$ of $0.33 \pm 0.07)$.

273 Low SLR values were also found for conservation measures such as natural

274 restoration $(P N=5, P Y=9)$, level ditching $(P N=8, P Y=20)$, back-slope terracing

275 and ridge tillage $(P N=6, P Y=6)$ : For all these techniques the $S L R$ was around

2760.30 (Fig. 4a). Comparable SLR values were obtained for ridge tillage/field pitting 
$277(P N=12, P Y=25)$, fish-scale pitting $(P N=7, P Y=29)$, hedgerows $(P N=108, P Y$ $278=226)$ and intercropping $(P N=6, P Y=17)$, for which the $S L R$ was close to 0.40 .

279 No-tillage $(P N=49, P Y=175)$ had a slightly higher $S L R$ of ca. $0.46 \pm 0.05 . S L R$ 280 values for contour tillage $(P N=59, P Y=214)$ and strip intercropping $(P N=15, P Y$ $281=16)$ were higher than 0.50 but still lower than the $S L R$ under reduced tillage $(P N$ $282=6, P Y=6)$ which has a value of $1.17 \pm 0.32$. However, we only found two studies 283 that examined the performance of reduced tillage.

284 The most effective conservation technique in reducing runoff was also grass cover 285 with an $R R$ of $0.33 \pm 0.04(P N=44, P Y=145)$. Horizontal terracing, back-slope 286 terracing, ridge tillage/field pitting and fish-scale pitting also efficiently controlled 287 runoff generation in plots: the $R R$ of these techniques were all close to 0.40 . The $288 R R$ for intercropping, level ditching, mulching, hedgerows and ridge tillage varied 289 between ca. 0.50 and ca. 0.58 which was lower than the $R R$ of the two tillage 290 measures (contour tillage and no-tillage) for which a $R R$ of ca. 0.70 was found. 291 Strip intercropping and reduced tillage did not allow to control runoff: the average $292 R R$ for these SWCMs exceeded 1 (Table 3 and Fig. 4b).

293 Table 3 The summary of soil loss ratio $(S L R)$ and runoff ratio $(R R)$ for each soil 294 conservation and water conservation measure in paired erosion plot database. The mean 295 of $S L R$ and $R R$ were weighted by the plot years. SD is the standard deviation. SE is the 296 standard error of mean.

\begin{tabular}{|c|c|c|c|c|c|c|c|c|c|c|c|c|}
\hline \multirow{2}{*}{ SWCMs } & \multicolumn{6}{|l|}{ SLR } & \multicolumn{6}{|l|}{$\mathrm{RR}$} \\
\hline & mean & median & $\mathrm{PN}$ & PY & SD & SE & mean & median & $\mathrm{PN}$ & PY & SD & SE \\
\hline Contour tillage & 0.55 & 0.47 & 59 & 214 & 0.38 & 0.05 & 0.7 & 0.62 & 55 & 160 & 1.22 & 0.16 \\
\hline No-tillage & 0.46 & 0.64 & 49 & 175 & 0.38 & 0.05 & 0.68 & 0.68 & 39 & 97 & 0.36 & 0.06 \\
\hline Reduced tillage & 1.17 & 1.17 & 6 & 6 & 0.78 & 0.32 & 1.06 & 1.01 & 10 & 18 & 0.18 & 0.06 \\
\hline Ridge tillage & 0.34 & 0.38 & 6 & 6 & 0.26 & 0.11 & 0.54 & 0.61 & 6 & 6 & 0.35 & 0.14 \\
\hline Ridge tillage/field pitting & 0.37 & 0.40 & 12 & 25 & 0.25 & 0.07 & 0.40 & 0.40 & 12 & 25 & 0.25 & 0.07 \\
\hline Fish-scale pitting & 0.37 & 0.36 & 7 & 29 & 0.36 & 0.14 & 0.45 & 0.39 & 6 & 28 & 0.36 & 0.15 \\
\hline
\end{tabular}




\begin{tabular}{lllllllllllll} 
Back-slope terracing & 0.32 & 0.09 & 14 & 39 & 0.43 & 0.11 & 0.38 & 0.37 & 12 & 37 & 0.20 & 0.06 \\
Horizontal terracing & 0.33 & 0.18 & 66 & 240 & 0.56 & 0.07 & 0.40 & 0.40 & 44 & 142 & 0.28 & 0.04 \\
Level ditching & 0.30 & 0.29 & 8 & 20 & 0.25 & 0.09 & 0.53 & 0.47 & 8 & 20 & 0.13 & 0.05 \\
Grass cover & 0.15 & 0.16 & 48 & 164 & 0.22 & 0.03 & 0.33 & 0.35 & 44 & 145 & 0.26 & 0.04 \\
Hedgerows & 0.40 & 0.34 & 108 & 226 & 0.47 & 0.05 & 0.58 & 0.64 & 75 & 145 & 0.27 & 0.03 \\
Intercropping & 0.41 & 0.48 & 6 & 17 & 0.15 & 0.06 & 0.50 & 0.61 & 6 & 17 & 0.42 & 0.17 \\
Mulching & 0.18 & 0.32 & 4 & 9 & 0.27 & 0.14 & 0.53 & 0.71 & 3 & 8 & 0.49 & 0.28 \\
Natural restoration & 0.23 & 0.07 & 5 & 9 & 0.32 & 0.14 & - & - & - & - & - & - \\
Strip intercropping & 0.61 & 0.44 & 15 & 16 & 0.58 & 0.15 & 1.51 & 0.93 & 15 & 16 & 2.41 & 0.62 \\
\hline
\end{tabular}



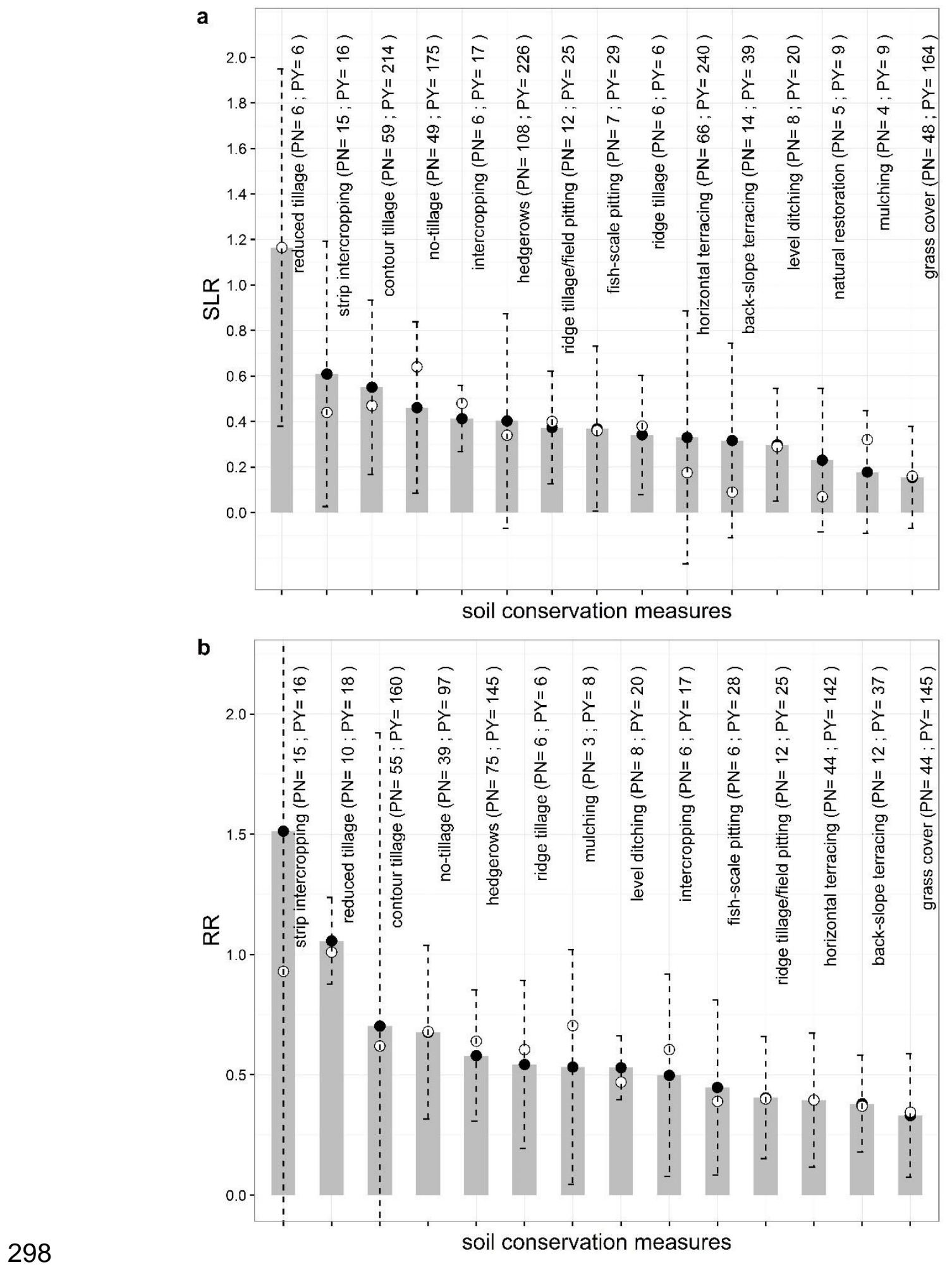

299 Fig. $4 S L R$ (a) and $R R$ (b) for different SWCMs. The black and white dot is the weighted 300 mean value and median of $S L R$ and $R R$, respectively. The dashed line is the standard 301 deviation of the mean. 
302 The comparison of the weighted mean $S L R$ and $R R$ calculated for the different 303 SWCMs suggested that, similar to what was observed by Maetens et al. (2012), 304 all SWCMs except reduced tillage were more efficient in reducing soil loss than 305 runoff (Fig. 5).

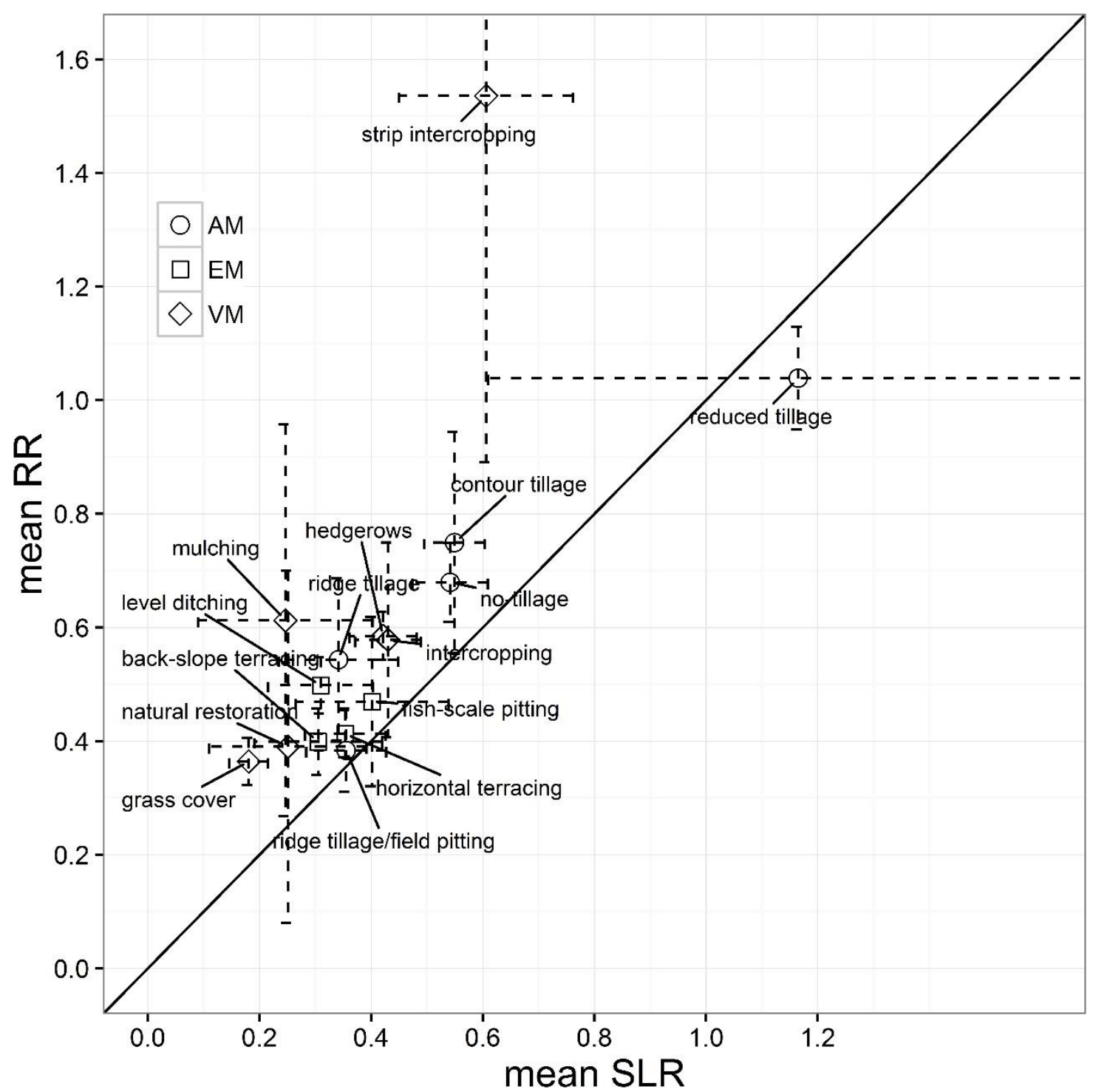

307 Fig. 5 Comparison of weighted mean runoff ratio $(R R)$ and soil loss ratio $(S L R)$ for each 308 SWCM: dotted lines indicate the weighted standard deviation of the mean. 
309 When the variation in efficacy of the five most frequently reported soil and water 310 conservation measures in our database (contour tillage, no-tillage, horizontal 311 terracing, grass cover and hedgerows) is compared, it becomes clear that 312 horizontal terracing and grass cover show a higher soil conservation efficacy than 313 hedgerows and tillage measures (contour tillage and no-tillage) (Fig. 6a). Trends 314 with respect to the efficacy of runoff control were similar. Wilcoxon Nonparametric 315 Tests indicated that horizontal terracing and grass cover reduced runoff more than 316 hedgerows and tillage measures $(p<0.001)$ (Table 4 and Fig. $6 b)$.

317 Table 4 Wilcoxon two-samples nonparametric tests of $S L R$ and $R R$ for five SWCMs. 318 Average and standard deviation as calculated for two techniques are given on each row. 319 When values are given in bold they were significantly different at the 0.05 level

\begin{tabular}{|c|c|c|}
\hline & SLR & RR \\
\hline contour tillage (grass cover) & $0.55 \pm 0.05(0.15 \pm 0.03)$ & $0.62 \pm 0.16(0.35 \pm 0.04)$ \\
\hline contour tillage (hedgerows) & $0.55 \pm 0.05(0.40 \pm 0.05)$ & $0.62 \pm 0.16(0.64 \pm 0.03)$ \\
\hline contour tillage (no-tillage) & $0.55 \pm 0.05(0.46 \pm 0.05)$ & $0.62 \pm 0.16(0.68 \pm 0.06)$ \\
\hline contour tillage (horizontal terracing) & $0.55 \pm 0.05(0.33 \pm 0.07)$ & $0.62 \pm 0.16(0.40 \pm 0.04)$ \\
\hline grass cover (hedgerows) & $0.15 \pm 0.03(0.40 \pm 0.05)$ & $0.35 \pm 0.04(0.64 \pm 0.03)$ \\
\hline grass cover (no-tillage) & $0.15 \pm 0.03(0.46 \pm 0.05)$ & $0.35 \pm 0.04(0.68 \pm 0.06)$ \\
\hline grass cover (horizontal terracing) & $0.15 \pm 0.03(0.33 \pm 0.07)$ & $0.35 \pm 0.04(0.40 \pm 0.04)$ \\
\hline hedgerows (no tillage) & $0.40 \pm 0.05(0.46 \pm 0.05)$ & $0.64 \pm 0.03(0.68 \pm 0.06)$ \\
\hline hedgerows (horizontal terracing) & $0.40 \pm 0.05(0.33 \pm 0.07)$ & $0.64 \pm 0.03(0.40 \pm 0.04)$ \\
\hline no-tillage (horizontal terracing) & $0.46 \pm 0.05(0.33 \pm 0.07)$ & $0.68 \pm 0.06(0.40 \pm 0.04)$ \\
\hline
\end{tabular}

320. 

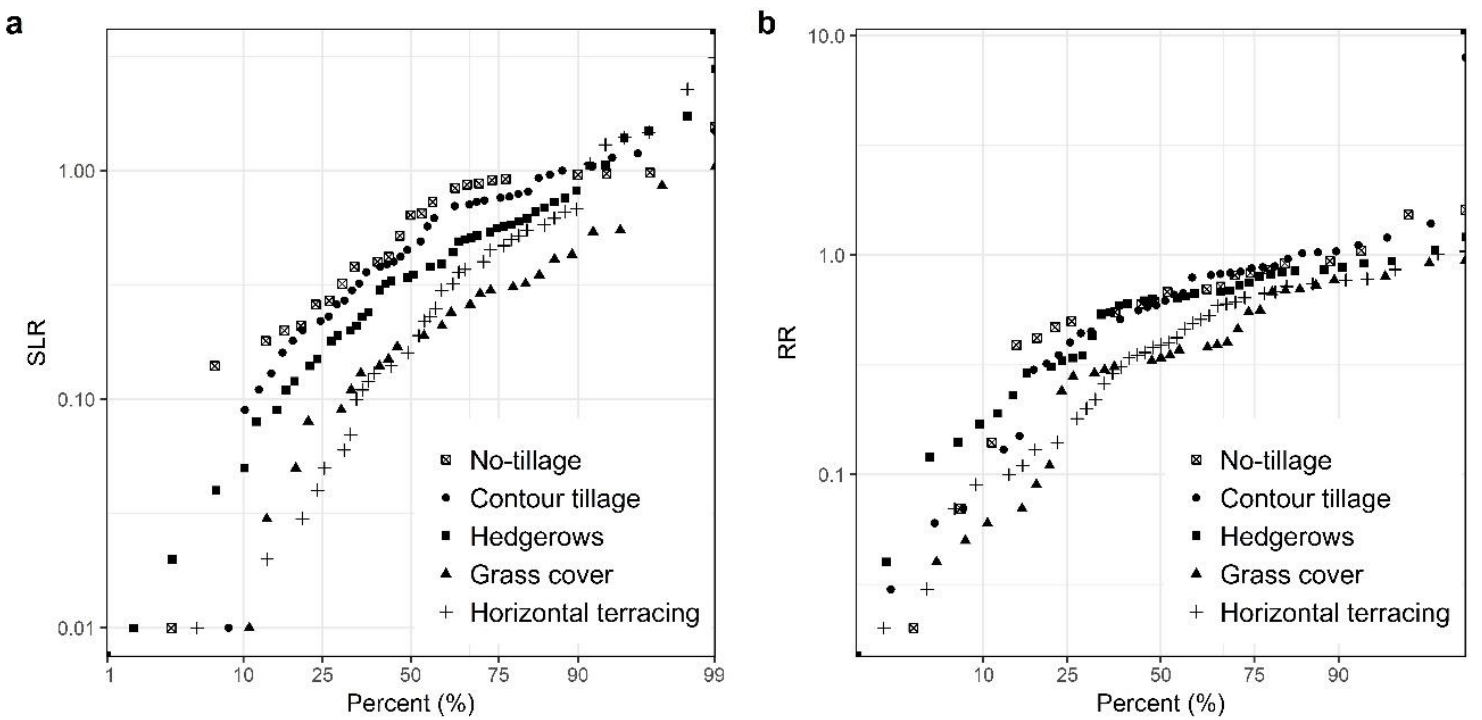

321

322 Fig. 6 Empirical cumulative distributions plot of $S L R$ (a) and $R R$ (b) for the five most 323 frequently reported SWCMs.

\section{3.3. Factors controlling $S L R$ and $R R$}

325 Our analysis showed that, when all SWCMs were considered, SLR was 326 significantly $(p<0.05)$ positively related to $S, S L$ and $R$ while it was significantly 327 negatively related to $L$ (Table 5). Slope gradient and slope length only explained a 328 marginal fraction of total variance in $\ln (S L R)(1.76 \%$ and $1.31 \%$, respectively). Soil 329 loss rate, on the other hand, explained $15.10 \%$ of the variance of $S L R$. The positive 330 relation between the SLR and SL contrasts with the results of Maetens et al. (2012) 331 who found that SWMCs were more efficient when erosion rates were higher in 332 Europe and the southern Mediterranean. The variation of $\ln (R R)$ was also 333 significantly positively related to $S, S L$ and $R$. For the five most reported SWCMs 334 we found that $S L R$ and $R R$ were significantly positively related to $S L, R$ and $335 \mathrm{~S}$ (Table 5). The results were less consistent for annual precipitation $(P)$ which 336 explained a large fraction of the variation in SLR for grass cover (51.60\%) and 
337 hedgerow (25.60\%) and a large part of the variation in $R R$ for grass cover (34.20\%),

338 hedgerow (55.10\%) and contour tillage (17.60\%) (Table 5). The significant

339 relations between $S L R$ and $S L$ as well as between $R R$ and $R$ should be interpreted

340 with caution as this the correlation is to some extent spurious, given that the

341 amount of soil loss and runoff are used to calculate $S L R$ and $R R$. Hence, soil loss

342 and runoff are present in both the dependent and independent variables.

343 Table 5 Regression analysis (Eq. (3)) between controlling factors (natural logarithm of 344 annual precipitation $(P)$, slope length $(L)$, slope gradient $(S), S L$ and $R$ ) and the natural 345 logarithm of the response variables $R R$ and $S L R$. We only listed the factors which 346 significantly correlated with $S L R$ and/or $R R(p<0.05)$.

\begin{tabular}{llllllll}
\hline$Y$ & $X$ & SWCMs & $a$ & $b$ & $r^{2}$ & $p$ & $n$ \\
\hline $\operatorname{Ln}(R R)$ & $\operatorname{Ln}(P)$ & contour tillage & -8.00 & 1.10 & 0.18 & $\mathrm{p}<0.05$ & 33 \\
& & grass cover & 8.50 & -1.50 & 0.34 & $\mathrm{p}<0.001$ & 31 \\
& & hedgerows & -12.00 & 1.60 & 0.55 & $\mathrm{p}<0.001$ & 41 \\
& $\operatorname{Ln}(S)$ & all plots & -1.60 & 0.31 & 0.04 & $\mathrm{p}<0.001$ & 241 \\
& & contour tillage & -1.90 & 0.52 & 0.13 & $\mathrm{p}<0.05$ & 39 \\
& hedgerows & -2.90 & 0.81 & 0.52 & $\mathrm{p}<0.001$ & 42 \\
& $\operatorname{Ln}(R)$ & all plots & -1.60 & 0.20 & 0.10 & $\mathrm{p}<0.001$ & 232 \\
& & contour tillage & -1.60 & 0.25 & 0.19 & $\mathrm{p}<0.01$ & 38 \\
& hedgerows & -2.90 & 0.55 & 0.63 & $\mathrm{p}<0.001$ & 42 \\
& $\operatorname{Ln}(S L)$ & no-tillage & -1.40 & 0.29 & 0.16 & $\mathrm{p}<0.05$ & 27 \\
& & all plots & -1.10 & 0.26 & 0.31 & $\mathrm{p}<0.001$ & 230 \\
& contour tillage & -0.94 & 0.22 & 0.30 & $\mathrm{p}<0.001$ & 33 \\
& grass cover & -1.40 & 0.50 & 0.79 & $\mathrm{p}<0.001$ & 38 \\
& hedgerows & -0.95 & 0.25 & 0.48 & $\mathrm{p}<0.001$ & 42 \\
& & Horizontal & & & & & \\
& & terracing & -1.40 & 0.31 & 0.27 & $\mathrm{p}<0.001$ & 44 \\
\hline $\operatorname{Ln}(S \ln )$ & $\operatorname{Ln}(P)$ & grass cover & 15 & -2.5 & 0.52 & $\mathrm{p}<0.001$ & 26 \\
& & hedgerows & -14 & 1.8 & 0.26 & $\mathrm{p}<0.001$ & 55 \\
& $\operatorname{Ln}(L)$ & all plots & -0.44 & -0.35 & 0.01 & $\mathrm{p}<0.05$ & 305 \\
& & hedgerows & 0.99 & -0.83 & 0.11 & $\mathrm{p}<0.01$ & 59 \\
& $\operatorname{Ln}(S)$ & all plots & -2.1 & 0.27 & 0.02 & $\mathrm{p}<0.05$ & 310 \\
& & hedgerows & -3.8 & 0.94 & 0.27 & $\mathrm{p}<0.001$ & 59 \\
\hline & & & & & &
\end{tabular}




\begin{tabular}{lllllll}
\hline & Horizontal & -3.9 & 0.77 & 0.10 & $\mathrm{p}<0.05$ & 58 \\
& terracing & & & & & \\
& all plots & -2.1 & 0.2 & 0.05 & $\mathrm{p}<0.01$ & 233 \\
& contour tillage & -2.3 & 0.36 & 0.19 & $\mathrm{p}<0.05$ & 31 \\
& hedgerows & -3.3 & 0.51 & 0.22 & $\mathrm{p}<0.01$ & 41 \\
& no-tillage & -1.7 & 0.35 & 0.17 & $\mathrm{p}<0.05$ & 24 \\
$\operatorname{Ln}(S L)$ & all plots & -1.7 & 0.29 & 0.15 & $\mathrm{p}<0.001$ & 301 \\
& contour tillage & -1.5 & 0.35 & 0.30 & $\mathrm{p}<0.001$ & 44 \\
& grass cover & -2.6 & 0.59 & 0.37 & $\mathrm{p}<0.001$ & 37 \\
& hedgerows & -1.5 & 0.27 & 0.18 & $\mathrm{p}<0.001$ & 59 \\
& Horizontal & -2 & 0.23 & 0.07 & $\mathrm{p}<0.05$ & 59 \\
& terracing & & & & & \\
\hline
\end{tabular}

347 We also investigated the combined effect of the different independent variables

348 through stepwise regression analysis: in this analysis, we excluded the $S L$ for the

349 regression on $S L R$ and excluded $S L$ and $R$ for the regression on $R R$ (Table 6).

350 When all SWCMs plots are included, a multiple linear regression showed that slope

351 length has a significant negative effect on both $S L R$ and $R R$ : The combination of

352 slope length, $R$ and $P$ explained $14 \%$ of variance of $\ln (S L R)$, while only slope length

353 was selected as an effective predictor for $\ln (R R)$ which explained $5 \%$ of the

354 variation of $\ln (R R)$ (Table 6). When SWCMs were considered separately, slope

355 length was also added as a significant factor in the regression model. The $S L R$ for

356 grass cover and no-tillage were negatively related to slope length as well as the

$357 R R$ for hedgerows and no-tillage. The fact that slope length was negatively related

358 to both SLR and RR for many SWCMs suggests that the efficacy of SWMCs

359 increased on longer slopes (Table 6). Although slope gradient and precipitation

360 frequently presented in the final equation of $\ln (S L R)$ and $\ln (R R)$, the relative

361 contribution of these factors on the efficacy of different SWCMs, expressed in

362 relative term, was not consistent: precipitation positively relates to $S L R$ for all plots 
363 but negative to $S L R$ for grass cover and horizontal terracing. The inconsistency of

364 the role of slope gradient and precipitation in different SWCMs might due to the

365 difference of undying mechanisms of SWCMs on reducing soil and water erosion

366 and the limited number of observations we collected in this study.

367 Table 6 Results of stepwise linear regression analysis. $R$ and $S L$ was excluded from the 368 regression of $R R$, while $S L$ was excluded from the regression of $S L R$. Ns indicated no 369 significant relation was able to be detected from the stepwise linear regression analysis.

\begin{tabular}{llll}
\hline SWCMs & \multicolumn{1}{c}{ Equation } & $n$ & $r^{2}$ \\
\hline \multirow{2}{*}{ All plots } & $\ln (R R)=0.24-0.50 \ln (L)^{*}$ & 177 & 0.05 \\
& $\ln (S L R)=4.18-0.85 \ln (P)-0.58 \ln (L)+0.46 \ln (R)$ & 175 & 0.14 \\
Contour tillage & $\ln (R R)=-9.99+1.20 \ln (P)+0.48 \ln (S)$ & 30 & 0.34 \\
& $\ln (S L R)=-3.64+0.63 \ln (R)^{*}$ & 23 & 0.40 \\
Grass cover & $\ln (R R)=9.24-1.96 \ln (P)+1.11 \ln (S)$ & 31 & 0.50 \\
\multirow{2}{*}{ Hedgerows } & $\ln (S L R)=36.86-4.38 \ln (P)-3.06 \ln (L)-2.0 \ln (S)+1.35 \ln (R)$ & 26 & 0.72 \\
& $\ln (R R)=-7.10+1.11 \ln (P)-0.44 \ln (L)+0.40 \ln (S)$ & 41 & 0.65 \\
No-tillage & $\ln (S L R)=-3.97+1.03 \ln (S)^{*}$ & 40 & 0.40 \\
& $\ln (R R)=1.76-1.21 \ln (L)^{*}$ & 25 & 0.15 \\
Horizontal terracing & $\ln (S L R)=-0.47-0.97 \ln (L)+0.87 \ln (R)$ & 22 & 0.73 \\
& $\mathrm{Ns}$ & - & - \\
\hline
\end{tabular}

370 * These equation was finally presented in a single linear equation and was not consistent 371 with the result in Table 5. This is mainly due to the fact that stepwise linear regression 372 required complete data for all variable. Therefore, observations with non-data were 373 removed from the regression analysis. Thus, the number of observation $(n)$ used for the 374 regression procedure in table 5 and table 6 was different.

\section{4. Discussion}

376 4.1. Efficacy of soil conservation measures in China

377 Clearly, soil conservation measures, on average, allow to considerable reduce soil

378 losses in China. This is consistent with the results of Leys et al. (2010), Maetens 379 et al. (2012) and Montgomery (2007) as well as many other studies that reported 380 that soil loss rates under conventional agriculture were generally one to two orders 381 of magnitude larger than soil loss rates under soil conservation practice 
382 (conservation tillage) worldwide. When assuming a soil loss tolerance level of $10 \mathrm{t}$ $383 \mathrm{ha}^{-1} \mathrm{yr}^{-1}$ ( $T$ value, Schertz, 1983), our results indicate that the application of

384 SWCMs can reduce the probability of the soil loss rate to exceed the $T$ value by 385 ca. $36 \%$ (Fig. 7). This reduction is smaller than that reported by Montgomery (2007) 386 who found a reduction by $75 \%$ when conservation tillage was applied, but it is 387 larger than the value of $14 \%$ that was found for European and Southern 388 Mediterranean plots (Maetens et al., 2012).

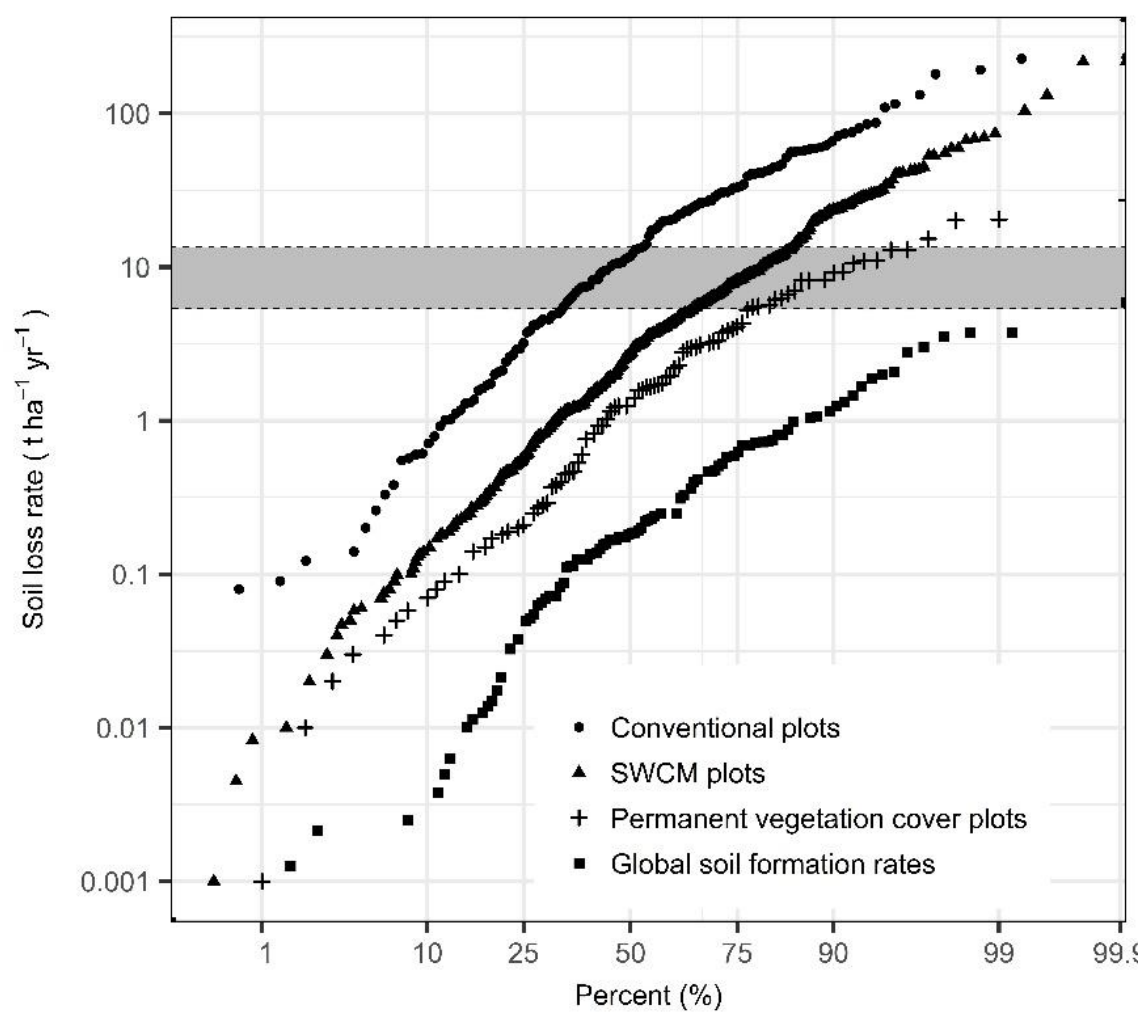

390 Fig. 7 Empirical cumulative distributions plots of soil loss rate for conventional plots, 391 SWCM plots and permanent vegetation cover plots in China and Global soil formation 392 rates. The Global soil formation rates were extracted from Stockmann et al. (2014). 


\subsection{Factors controlling SLR and RR}

394 Both the SLR and RR showed a large variation for different SWCMs (Fig. 5). Our 395 regression analysis indicates that the $\ln (S L R)$ and $\ln (R R)$ of few SWCMs shows a 396 significant relationship with our defined controlling factors (slope gradient, slope 397 length, precipitation) (Table 5). Only a limited fraction of the variation of $\ln (R R)$ and $398 \ln (S L R)$ was explained by these factors which is consistent with the result observed 399 in the European and Mediterranean region (Maetens et al., 2012). But the influence 400 of these factors on the efficacy of SWCMs, expressed in relative term, varies for 401 different SWCMs (Table 5). In general, slope length negatively relates to SLR and $402 R R$, whereas a positive relationship between $S L R$ and $R R$ and slope gradient and 403 precipitation was found. Previous studies also argued the role of a single 404 controlling factor on the contribution to the efficacy of SWCMs. For example, 405 Maetens et al. (2012) reported that all controlling factors (slope length, slope 406 gradient and precipitation) negatively related to $S L R$. Assessing the efficacy of 407 SWCMs in Ethiopia indicates that some SWCMs such as soil bunds, stone bunds, 408 and grass strips are more effective under low rainfall areas, while grass waterways 409 are more effective under high rainfall regime (Kato et al., 2011). Although the 410 positive effection of slope on the efficacy of terrace in China was reported, it was

411 only valid when slope gradient is lower than 15 degrees (Chen et al., 2017).

412 Meanwhile, a recent global review study indicates that soil conservation efficacy 413 increase with the rise of slope gradient in the bare land plot, but the reverse 414 tendency was observed in other land use plots (cropland and orchards) (Xiong et 415 al., 2018). 
416 The limited and inconsistent influence of a controlling factor on the efficacy of 417 SWCMs may be attributed to the fact that other environmental factors such as soil

418 properties, topography, land cover and climate (Maetens et al., 2012; Taye et al., 419 2013) also contribute to the variation of SWCMs efficacy. For instance, Shen et al. 420 (2010) found that the efficacy of SWMCs was related to the specific technique 421 used. Level terracing with different types of terrace banks (risers) resulted in 422 different efficacies: soil risers resulted in SLR values that were about two times 423 higher than stone and grass risers (Shen et al., 2010). Similarly, the number of 424 planting rows, the type of plant and the horizontal spacing of hedgerows all affect 425 the efficacy of a hedgerow system for controlling of soil loss and runoff (Rodríguez, 426 1997; Zhang et al., 2011). The efficacy of no-tillage for erosion control was found 427 to be strongly dependent on the amount of residue left on the surface (Basic et al., 428 2004; Kassam et al., 2011). Therefore, identifying a controlling factor for the 429 efficacy of a single SWCMs requires more detailed and sophisticated experimental 430 studies when influences from other relevant factors were eliminated.

431 Nevertheless, the single and combined regression analysis in this study suggests 432 the critical influence of slope gradient and slope length on the efficacy of SWCMs 433 (Table5 and Table 6). The fact that the effectiveness of SWCMs is affected by 434 topography implies that the comparison of soil conservation efficacy might be 435 biased as there may also be a relationship between the SWCM technique that is 436 used and slope gradient. Comparing plot slope gradient for the five most frequently 437 tested SWCMs indicated that horizontal terracing and hedgerows were, on 438 average, evaluated on plots having a steeper slope gradient in comparison to the 
439 plots on which contour tillage, no-tillage and grass cover were applied (Fig. 8).

440 Importantly, regression analysis indicated that $S L R$ was significantly positively

441 correlated to slope gradient for horizontal terracing and hedgerows (Table 5). This

442 suggests that the direct comparison of the conservation efficacy or SLR of

443 horizontal terracing and hedgerows with the other techniques may lead to a relative

444 underestimation of the efficacy of horizontal terracing and hedgerows (or

445 overestimated the $S L R$ ), given that the higher average $S L R$ values obtained for

446 these techniques are at least partly due to a slope effect (Fig. 8). Based on our

447 regression analysis (Table 5), the $S L R$ for terracing and hedgerows on a $12^{\circ}$ slope

448 would be 0.23 and 0.21 , respectively, which is considerably lower than the directly

449 measured values (Fig. 8). 


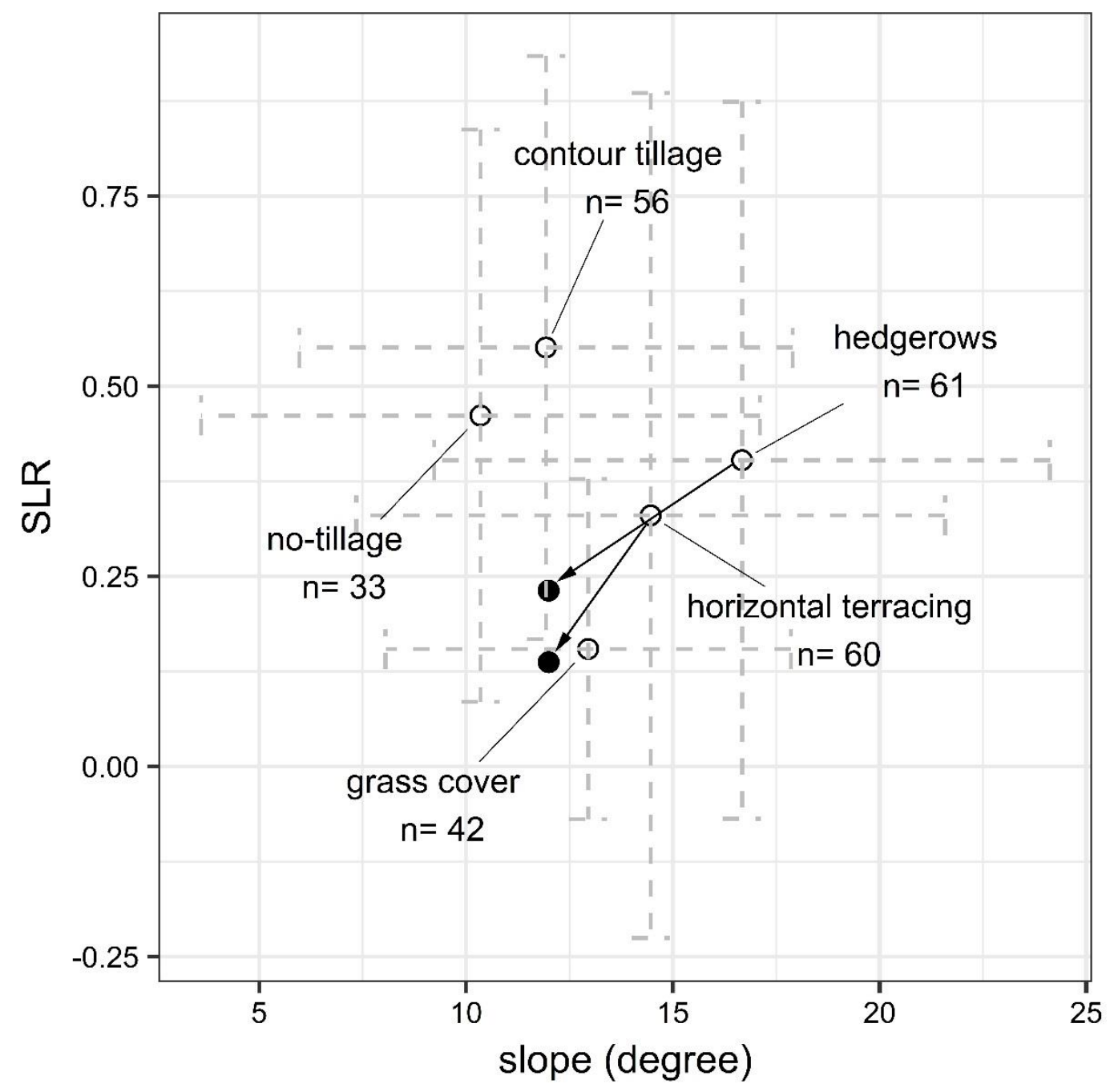

451 Fig 8 Mean and standard deviation of SLR VS mean slope (white dots) for the five most 452 reported SWCMs. The black dots and arrows illustrated the change of the estimated SLR 453 for horizontal terracing and hedgerows on a slope of $12^{\circ}$ respectively.

454 We also found that the efficacy of conservation measures, expressed in relative

455 terms, increases with slope length. Slope length positively affects efficacy (in terms

456 of erosion reduction) for those measures that lead to an increase of surface covers

457 such as the planting of grass or hedgerows and no-tillage. Slope length also has

458 a positive effect on runoff reduction when grass cover or no-tillage is used. 
459 This is important as it suggests that the support practice factor ( $P$ factor) of the 460 Revised Universal Soil Loss Equations (RUSLE, Renard et al., 1997) might be 461 overestimated when values obtained from plot studies are directly applied to 462 assess the impact of erosion control measures on larger areas. For example, the 463 measured slope length for non-terraced and terraced fields on the Chinese loess 464 plateau was, on average, ca. 62 meter and 25 meter, respectively (Zhao et al., 465 2016a). This is ca. 3 and 1.25 times longer than the average slope length in our 466 erosion plots (ca. 20 m, Fig. 2b). Our regression results (Table 6) indicate that the 467 efficacy of no-tillage may be underestimated by a factor of 2.74 and 1.2 if the $P$ 468 factor observed from erosion plots directly applied to terraced and non-terraced 469 arable land on the Chinese loess plateau, respectively. The efficacy of a technique 470 such as no-tillage and terrace may therefore be significantly larger under real field 471 conditions in comparison to erosion plot results.

472 These findings agree with earlier studies: Smets et al. (2008) examined the impact

473 of plot length on the efficacy of rock fragments, organic mulches and vegetation

474 cover on reducing soil and runoff and reported that these measures were more 475 effective with an increasing of plot length; Leys et al. (2010) showed that 476 conservation tillage measures did become more effective in reducing erosion and 477 runoff on arable land on longer slopes and extensively discussed the possible 478 mechanisms explaining this: when a larger fraction of the land is covered with 479 vegetation both the increase of total runoff and the increase of runoff erosivity are 480 reduced as infiltration rates increase with increasing water depth, causing a 481 negative feedback (Dunne et al., 1991; El Kateb et al., 2013; Fox et al., 1997). 
482 Other factors that are likely playing a role here are the effect of vegetation or 483 vegetation residues on runoff patterns: when vegetation is present runoff is less

484 likely to become concentrated, thereby reducing its erosivity (Armand et al., 2009;

485 Bradford and Huang, 1994). The latter will not only reduce its erosivity but will also 486 increase the probability of infiltration by increasing the residence time of the water 487 within the plot/field.

488 Our study shows that a similar trend is present when a grass cover is installed. 489 This is not surprising given that similar mechanisms than those observed on 490 conservation tilled land (flow retardation, increasing infiltration) may be expected 491 to occur when a permanent vegetation cover is present (Fox et al., 1997; Leys et 492 al., 2010).

493 4.3. Does soil conservation adequately protect soils in China?

494 Importantly, erosion rates on plots with SWCMs in China were, in general, still 495 significantly higher than erosion rates measured under permanent vegetation 496 cover land and, on average, ca. one order of magnitude higher than soil formation 497 rates derived from a database which covering a wide range of environments 498 (Stockmann et al., 2014)(Fig. 9).

499 The discrepancy between the erosion rates measured under permanent 500 vegetation and the soil production rates published by Stockmann et al. (2014) may 501 have several reasons. First, as discussed above, erosion plot measurements may 502 not completely represent average erosion rates. Especially under permanent 503 vegetation average hillslope erosion rates may be lower than those observed on 
504 erosion plots due to the discontinuous nature of runoff and erosion under these 505 conditions so that erosion rates measured on plots might be higher than soil 506 production rates (Cerdan et al., 2004). However, Montgomery (2007) did not 507 observe such a discrepancy: in his study plots under natural vegetation had 508 erosion rates very similar to the soil production rates, suggesting that, despite the 509 fact that erosion plot studies may not fully representative for hillslope erosion, the 510 bias on observed erosion rates is limited. It is also possible that soil production 511 rates in China are, on average, higher than the global distribution compiled by 512 Stockmann et al. (2014) suggests. This appears to be unlikely as well: the global 513 database on soil production rates covers a wide range of climatic and soil 514 conditions and it seems unlikely that, on average, soil production rates in China 515 would, on average, be an order of magnitude higher (which would be necessary to 516 match the erosion rates observed under natural vegetation). The most likely 517 explanation is, in our view, suggested by the observation that the erosion rates 518 under permanent vegetation that we compiled for China are, on average, ca. 1 519 order of magnitude larger than those compiled for native vegetation by 520 Montgomery (2007) (Fig. 9). The higher erosion rates observed on plots with 521 permanent vegetation in China may be related to the fact that, also on these plots, 522 vegetation is somewhat degraded by human use. This leads to a reduction of 523 vegetation biomass (Erb et al., 2017) which may therefore have become less 524 effective than the pristine vegetation in protecting the soil so that erosion is 525 accelerated. Absolute erosion rates, however, remain, on average, relatively low. 
526 It therefore seems reasonable to compare the erosion rates measured under plots 527 with SWCMs in China to the global distribution of soil production rates, albeit with 528 caution. It can then easily be observed that, while SWCMs do reduce erosion 529 significantly, measured erosion rates remain, on average, more than one order of 530 magnitude higher than soil production rates, suggesting that the equilibrium 531 between erosion and soil production is not fully re-established. Several factors may 532 be suggested that contribute to this discrepancy. First, plot measurements may 533 underestimate the efficacy of some SWCMs as measured efficacy increases with 534 plot length (see discussion above): this however, is unlikely to fully explain the 535 observed difference. Second, agricultural land in China is often located on 536 moderate to steep slopes and the implementation of soil conservation measures 537 may indeed become less effective with increasing slope gradient (Fig. 2a). This is 538 not unexpected, given that many SWCMs such as ridging and pitting are based on 539 the storage of excess runoff water on the field, which will tend to become less 540 effective with increasing slope gradient. Other techniques may also become less 541 effective: Shen et al. (2010) indicated that the efficacy of terracing in reducing soil 542 loss decreased with increasing slope gradient. We found that the $S L R$ was, on 543 average proportional to the slope gradient to an exponent 0.3 (see table 5), which 544 would result in an $S L R$ that is ca. $40 \%$ higher on a $15^{\circ}(26 \%)$ slope in comparison 545 to a $9 \%$ slope. Other factors, such as the type of crop and the type of soil may also 546 be important controls on SWCM efficacy but the currently available data do not 547 allow to assess their impact. 


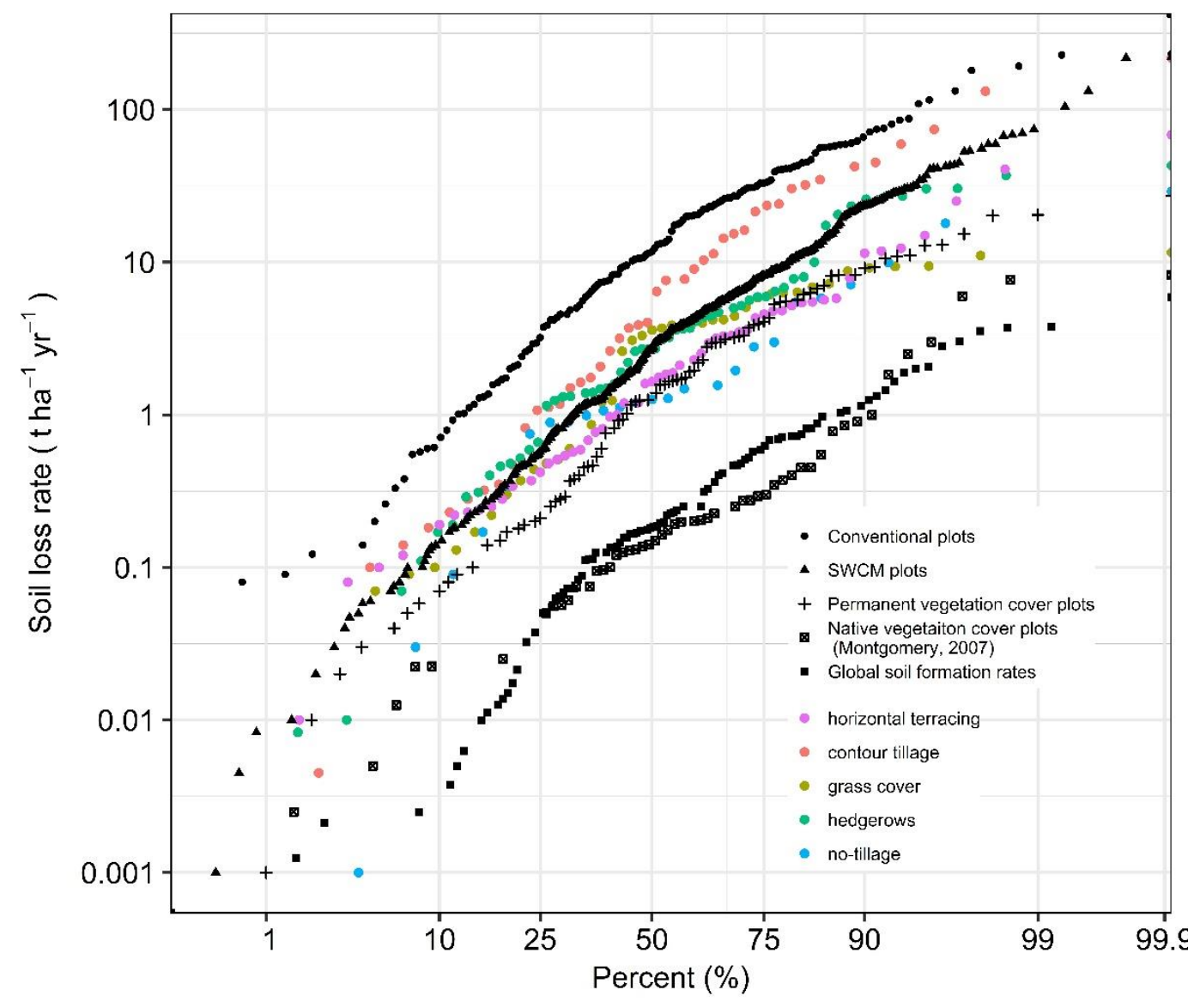

549 Fig. 9 Comparison of empirical cumulative distributions of soil loss rate for conventional 550 plots, all SWCMs plot and permanent vegetation cover plots in China, native vegetation 551 plot in Montgomery (2007), and Global soil formation rates with the empirical cumulative 552 distributions of soil loss rate for five most tested SWCMs.

553 Thus, the implementation of SWCMs strongly contributes to erosion reduction in

554 China but even soil and water conservation measures are applied, erosion rates

555 appear to significantly higher than the soil formation rate which required for a soil-

556 neutral agriculture. This suggests that, for some of the steepest agricultural land in

557 China, the best option may be to abandon agriculture and re-establish permanent

558 vegetation as is being stimulated by the Grain for Green program (Xiao, 2014).

559 Our analysis suggests, however, that even under permanent vegetation cover 560 average erosion rates may significantly exceed soil formation rates. Careful 
561 monitoring is then required to assess to what extent revegetation is indeed 562 successful in re-establishing an equilibrium between soil erosion and soil 563 production.

\section{5. Conclusions}

565 Our study evaluated the efficacy of soil and water conservation measures in 566 reducing soil loss and runoff at erosion plots in China based on a review of erosion 567 plot data. We presented the overall efficacy of SWCMs in controlling soil loss and 568 runoff and also compared the efficacy of single SWCMs. Our results suggested 569 that in general, applying the SWCMs can reduce soil loss by ca. 70\% (overall SLR

570 is $0.39 \pm 0.02$ ) and runoff by ca. $50 \%$ (overall $R R$ is $0.54 \pm 0.05$ ). The engineering 571 measures were, on average, more efficient than vegetation measures and 572 agricultural measures.

573 We examined five variables potentially effected the variation of $S L R$ and $R R$. We

574 found that slope length was, in general, significantly negatively related to SLR and $575 R R$ when all SWCMs plots were considered. The negative relation of slope length 576 with $S L R$ and $R R$ suggest that conservation measures become more effective at 577 larger scales, which is related to the effects of increasing cover on runoff and 578 sediment transport (grass, no-tillage) or on the increasing trapping efficacy with 579 slope length (hedgerows). However, this relation was absent for contour tillage and 580 horizontal terracing. The results of this study can be applied for the planning of 581 SWCMs in China to control soil erosion and runoff. The presented $S L R$ and $R R$ 582 values can be used to estimate the $P$ factor when the (R)USLE model is applied 
583 whereby the effect of slope gradient and slope length on SWCM efficacy can be

584 accounted for. However, as the variation of both $S L R$ and $R R$ was only partly

585 explained by the variable examined in this study, significant uncertainty will be

586 associated with the predicted efficacy.

587 For all SWCMs the application of conservation measures reduced soil loss more

588 than runoff with the exception of reduced tillage. However, the implementation of

589 SWCMs does not allow to reduce current soil loss rates in China to the levels of

590 soil formation rates: soil loss rates under SWCMs were, for most measures, still

591 higher than erosion rates under permanent vegetation cover and were one order

592 of magnitude higher than soil production rates. Setting land erosion-prone aside

593 so that permanent vegetation can recover, as advocated by the Grain for Green

594 program (Wang et al., 2014), may therefore be the best solution to reduce erosion

595 rates to sustainable levels.

596 Acknowledgments

597 This study is supported by the Fundamental Research Funds for the Central

598 Universities, China (300102268303) and the China Scholarship Council (CSC).

\section{References}

600 1. Armand, R., Bockstaller, C., Auzet, A.-V., Van Dijk, P., 2009. Runoff generation related to intra-field soil surface characteristics variability: Application to

603 conservation tillage context. Soil Tillage Res. 102, 27-37.

604 2. Bakker, M.M., Govers, G., Rounsevell, M.D.., 2004. The crop productivity-erosion

605 relationship: an analysis based on experimental work. CATENA 57, 55-76.

606 https://doi.org/10.1016/j.catena.2003.07.002 
3. Basic, F., Kisic, I., Mesic, M., Nestroy, O., Butorac, a, 2004. Tillage and crop management effects on soil erosion in central Croatia. Soil Tillage Res. 78, 197-206. https://doi.org/10.1016/j.still.2004.02.007

4. Bradford, J.M., Huang, C., 1994. Interrill soil erosion as affected by tillage and residue cover. Soil Tillage Res. 31, 353-361. https://doi.org/10.1016/01671987(94)90041-8

5. Cai, X., 2004. Benefits from Soil and Water Conservation Measures on Reducing Runoff and Sediments in Shixia Small Watershed. Resour. Sci. 26, 144-150.

6. Cerdan, O., Le Bissonnais, Y., Govers, G., Lecomte, V., Van Oost, K., Couturier, a., King, C., Dubreuil, N., 2004. Scale effect on runoff from experimental plots to catchments in agricultural areas in Normandy. J. Hydrol. 299, 4-14. https://doi.org/10.1016/j.jhydrol.2004.02.017

7. Chen, D., Wei, W., Chen, L., 2017. Effects of terracing practices on water erosion control in China: A meta-analysis. Earth-Science Rev. 173, 109-121. https://doi.org/10.1016/j.earscirev.2017.08.007

8. Chen, G., Fan, H., Chen, H., Dong Guoquan, 2006. Benefits of sediment reduction of soil conservation practices in the black region of Northeast China. Sci. Soil Water Conserv. 4, 13-17.

9. Chen, Q., Yuriy, S.K., Chen, Y., Li, X., Li, H., Song, C., Zhang, X., 2014. SEASONL VARIATIONS OF SOIL STRUCTURES AND HYDRAULIC CONDUCTIVITIES AND THEIR EFFECTS ON SOIL AND WATER CONSERVATION UNDER NO-TILLAGEAND REDUCED TILLAGE. ACTA Pedol. Sin. 51, 11-21. https://doi.org/10.11766/trxb201305280268

10. Chen, R., 2005. Study on the Rapid Restoration of Grass Coverage and Technique of Controlling Soil and Water Loss in Eroded Hilly Land. Subtrop. Soil Water Conserv. $17,14-16$.

11. Chen, S., Hua, L., He, Z., Wei, D., Xia Hou, G., Li, Y., 2002. Effect of soil erosion on soil properties in deep cultivated hill slope in loess plateau. Agro-environmental Prot. 21, 289-292.

12. Chen, S., Yang, Y., Lin, W., Li, T., 2006. Quantitative Research on Soil and Water Loss and Countermeasures in Man-Made Distroyed Red Soil Region in Subtropical Region of Fujian Province. J. Soil Water Conserv. 20, 6-10.

13. Chen, Y., Dai, X., 1996. reduction of soil and water loss in a Myrica rubra garden. Fujian Soil Water Conserv. 3, 45-47.

14. Chen, Y., Zhang, X., Li, S., 2011. Comparative Study on Conservational Tillage in Slope and Flat Farmland. Syst. Sci. Compr. Stud. Agric. 27, 485-489.

15. Chen, Z., Tian, F., Dong, J., 2015. The slope erosion sediment yield under different land use types in hilly area of Anhui province. J. Arid L. Resour. Environ. 29, 186191.

16. Chu, L., Wang, K., Bai, W., Li, T., Li, Y., Shu, J., 2010. Impact of Level Terrace on Runoff, Sediment and N \& P Loss from Sloping Filed. J. Soil Water Conserv. 24, 1-6.

17. Cui, Y., Han, Z., Cui, B., Liu, W., Su, N., 1994. Effect of No-tillage with Stalks Mulching on Controlling Runoff and Soil Loss. J. Shanxi Agric. Sci. 22, 20-21. 
649

650

651

652

653

654

655

656

657

658

659

660

661

662

663

664

665

666

667

668

669

670

671

672

673

674

675

676

677

678

679

680

681

682

683

684

685

686

687

688

689

690

691

692

18. Dunne, T., Zhang, W., Aubry, B.F., 1991. Effects of Rainfall, Vegetation, and Microtopography on Infiltration and Runoff. Water Resour. Res. 27, 2271-2285. https://doi.org/10.1029/91WR01585

19. El Kateb, H., Zhang, H., Zhang, P., Mosandl, R., 2013. Soil erosion and surface runoff on different vegetation covers and slope gradients: A field experiment in Southern Shaanxi Province, China. Catena 105, 1-10. https://doi.org/10.1016/j.catena.2012.12.012

20. Erb, K.-H., Kastner, T., Plutzar, C., Bais, A.L.S., Carvalhais, N., Fetzel, T., Gingrich, S., Haberl, H., Lauk, C., Niedertscheider, M., Pongratz, J., Thurner, M., Luyssaert, S., 2017. Unexpectedly large impact of forest management and grazing on global vegetation biomass. Nature. https://doi.org/10.1038/nature25138

21. Fan, D., Yu, X., Jia, G., Wang, H., Zhao, Y., 2015. Characteristics of soil erosion under different landuse types in upper area of miyun reservoir. Bullet Soil Water Conserv. 35, 5-8. https://doi.org/10.13961/j.cnki.stbctb.2015.01.002

22. Fan, X., Ma, Z., Yang, Q., Han, Y., Mahmood, R., Zheng, Z., 2014. Land use/land cover changes and regional climate over the Loess Plateau during 2001-2009. Part II: interrelationship from observations. Clim. Change. https://doi.org/10.1007/s10584014-1068-5

23. Fox, D.M., Bryan, R.B., Price, A.G., 1997. The influence of slope angle on final infiltration rate for interrill conditions. Geoderma 80, 181-194. https://doi.org/10.1016/S0016-7061(97)00075-X

24. Fu, B., Zhao, W., Chen, L., Zhang, Q., Lu, Y., Gulinck, H., Poesen, J., 2005. Assessment of soil erosion at large watershed scale using RUSLE and GIS: a case study in the Loess Plateau of China. L. Degrad. Dev. 16, 73-85. https://doi.org/10.1002/ldr.646

25. Fu, B.J., Meng, Q.H., Qiu, Y., Zhao, W.W., Zhang, Q.J., Davidson, D. a., 2004. Effects of land use on soil erosion and nitrogen loss in the hilly area of the Loess Plateau, China. L. Degrad. Dev. 15, 87-96. https://doi.org/10.1002/ldr.572

26. Fu, J., Jiang, Z., Yi, C., Zhang, W., Wang, Y., 2000. Studies on soil and water conservation benefit of contour hedgerows in arid hillside farmland. Tillage and Cutivation 38-40.

27. Fu, S., Liu, B., Lu, B., Yuan, A., Wang, N., 2009. Effect of soil conservation practice on runoff and sediment in upper reach of Guanting Reservoir. Sci. Soil Water Conserv. 7, 18-23.

28. Govers, G., Merckx, R., Van Oost, K., Van Wesemael, B., 2013. Managing Soil Organic Carbon for Global Benefits: A STAP Technical Report. Washington, D.C.

29. Gu, X., Yu, Z., Zhao, H., Ai, Z., Guo, W., 1994. Assessment of the efficient of different soil and water control measurments. Hebei For. Sci. 21-22.

30. Han, Y., Li, X., Duan, S., Yuan, A., Lu, B., 2010. Influence of soil and water conservation measures to runoff sediment and nutrien loss. Soil Water Conserv. China 34-37.

31. He, J., Cai, Q., Fang, H., Chen, X., 2009. Effect evaluation of spatial allocation of water and soil conservation measures in Zhangjiakou area. Trans. CSAE 25, 69-75.

32. Huang, C., Tan, W., Qin, W., Wei, G., Wu, M., Wei, Y., 2012. Study on soil and water loss in Karst forest in Mulun. Res. Soil Water Conserv. 19, 34-37. 
693

694

695

696

697

698

699

700

701

702

703

704

705

706

707

708

709

710

711

712

713

714

715

716

717

718

719

720

721

722

723

724

725

726

727

728

729

730

731

732

733

734

735

33. Huang, J., 2015. Benefits of soil and water conservation measures under different land-use patterns in Ninghua. J. Agric. 5, 57-61.

34. Huang, Y., Luo, X., Zheng, Z., Zhang, W., Huang, X., Zhan, J., 2009. Effects of different exploitation manners on soil and water losses in hilly orchard. Sci. Soil Water Conserv. 7, 30-34.

35. Huang, Y., Yang, X., Jiang, F., 2007. Effects of Different Ways of Sod in Eroded Slope Orchard on Soil and Fruit Tree Growth. J. Soil Water Conserv. 21, 111-114.

36. Jia, G.-M., Liu, B.-R., Wang, G., Zhang, B., 2010. The microbial biomass and activity in soil with shrub (Caragana korshinskii K.) plantation in the semi-arid loess plateau in China. Eur. J. Soil Biol. 46, 6-10. https://doi.org/10.1016/j.ejsobi.2009.10.002

37. Jiang, B., Zhao, S., Wei, D., Jin, L., Li, Y., Guo, W., Xu, M., Zhang, Z., 2015. Effect of Slope and Tillage Measures on Soil Erosion and Yield of Soybean. SOYBEAN Sci. 34, 238-242.

38. Jiang, N., Shao, M., 2011. Characteristics of soil and water loss of different slope land uses in small watershed on the Loess Plateau. Trans. CSAE 27, 36-41.

39. Jin, K., Cai, D., Lu, J., Zhang, J., Wu, H., Rong, X., Gabriels, D., Schiettecatte, W., 2006. Effects of Tillage Practices on Erosion and Winter Wheat Yield on Sloping Dryland. J. Soil Water Conserv. 20, 1-5.

40. Kassam, A., Friedrich, T., Shaxson, F., Pretty, J., 2011. The spread of Conservation Agriculture: justification, sustainability and uptake. Int. J. Agric. Sustain. 7, 292-320.

41. Kato, E., Ringler, C., Yesuf, M., Bryan, E., 2011. Soil and water conservation technologies: A buffer against production risk in the face of climate change? Insights from the Nile basin in Ethiopia. Agric. Econ. 42, 593-604. https://doi.org/10.1111/j.1574-0862.2011.00539.x

42. Lal, R., 2003. Soil erosion and the global carbon budget. Environ. Int. 29, 437-50. https://doi.org/10.1016/S0160-4120(02)00192-7

43. Lal, R., 1998. Soil Erosion Impact on Agronomic Productivity and Environment Quality. CRC. Crit. Rev. Plant Sci. 17, 319-464. https://doi.org/10.1080/07352689891304249

44. Lan, J., Fan, H., Chai, Y., Zhou, L., Wu, M., 2009. Characteristics of Soil Erosion of Different Land Use Types in Earth-rock Low Mountainous Area in West of Liaoning. SOIL WATER Conserv. CHINA 329, 8-10.

45. Leys, A., Govers, G., Gillijns, K., Berckmoes, E., Takken, I., 2010. Scale effects on runoff and erosion losses from arable land under conservation and conventional tillage: The role of residue cover. J. Hydrol. 390, 143-154. https://doi.org/10.1016/j.jhydrol.2010.06.034

46. Li, X., Zhang, X., Gao, Y., Chen, Y., Li, H., Tao, S., Song, C., 2013. Benefits Aessessment for Soil and Water Conservation Projects in Black Soil Region of Northest China. Bullet Soil Water Conserv. 33, 43-47.

47. Li, Y., Quine, T.A.A., Yu, H.Q.Q., Govers, G., Six, J., Gong, D.Z.Z., Wang, Z., Zhang, Y.Z.Z., Van Oost, K., 2015. Sustained high magnitude erosional forcing generates an organic carbon sink: Test and implications in the Loess Plateau, China. Earth Planet. Sci. Lett. 411, 281-289. https://doi.org/10.1016/j.epsl.2014.11.036 
736

737

738

739

740

741

742

743

744

745

746

747

748

749

750

751

752

753

754

755

756

757

758

759

760

761

762

763

764

765

766

767

768

769

770

771

772

773

774

775

776

777

778

779

48. Lin, C., Tu, S., Huang, J., Chen, Y., 2007. The effects of plant hedgerows on soil erosion and soil fertility on sloping farmland in the purple soil area. Acta Ecol. Sin. 27, 2191-2198.

49. Liu, B., Liu, Y., Zhang, K., Xie, Y., 2013. Classification for soil conservation practices in China. J. Soil Water Conserv. 27, 80-84.

50. Liu, G., Gao, M., Zhang, J., Li, Y., Zhang, X., 2001. Soil Erosion Characteristics of Slope Land under Alternative Tillage Systems in Central Hilly Area of Sichuan, China. J. Mt. Sci. 19, 65-70.

51. Liu, L., 2007. Study on soil and water control measurements on the sloping orchard land. Hydraul. Sci. Technol. 16-17.

52. Liu, S.-Y., 2006. Comparative Study of Effects of Soil and Water Conservation on Sloping Land Orchard of Red Soil. Bull. Soil Water Conserv. 26, 7-10.

53. Lu, D., Li, G., Valladares, G.S., Batistella, M., 2004. Mapping soil erosion risk in Rondônia, Brazilian Amazonia: using RUSLE, remote sensing and GIS. L. Degrad. Dev. 15, 499-512. https://doi.org/10.1002/ldr.634

54. Lu, G., Ban, X., Lei, Z., Wu, X., 2009. Benefit of Soil and Water Conservation in the Process of Harnessing a Sloping Farmland in the Black Soil Region, Northeast China. Res. soil water Conserv. 16, 51-55.

55. Lu, H., Wang, H., Xie, Y., Wang, H., Li, X., Gao, G., 1996. A TENTATIVE STUDY ON SYNTHETIC EFFECT OF ZERO TILLAGE AND SOIL CONSERVATION ON SLOPING LAND OF YELLOW SPONGY SOIL IN EXPERIMENTAL AREAS OF LUANPING. Resour. Sci. 6871.

56. Lu, Y., Hu, W., Lei, B., Duan, Z., Liu, H., Zhai, L., 2010. The Monitoring of Nitrogen and Phosphorus Loss by Surface Runoff in Sloping Red Soil Fields of Yunan Province, China. J. Agro-Environment Sci. 31, 1544-1553.

57. Ma, J., Wang, Z., 2009. Soil and water conservation benefits of artificial grassland in Yanggao County. Soil Water Conserv. Sci. Technol. Shanxi 14-17.

58. Maetens, W., Poesen, J., Vanmaercke, M., 2012. How effective are soil conservation techniques in reducing plot runoff and soil loss in Europe and the Mediterranean? Earth-Science Rev. 115, 21-36. https://doi.org/10.1016/j.earscirev.2012.08.003

59. Mao, F., Wan, J., Tan, D., 2010. Soil and water loss and its countermeasures in Zhangjiachong watershed. Soil Water Conserv. China 59-61.

60. Mason, S.C., Ouattara, K., Taonda, S.J.-B., Palé, S., Sohoro, A., Kaboré, D., 2015. Soil and cropping system research in semi-arid West Africa as related to the potential for conservation agriculture. Int. J. Agric. Sustain. 13, 120-134. https://doi.org/10.1080/14735903.2014.945319

61. Meng, Q.H., Yang, L.Z., 2001. Effects of land use on soil erosion and nutrient loss in the Three Gorges Reservoir Area, China. Soil Use Manag. 17, 288-291. https://doi.org/10.1079/SUM200170

62. Mi, Y., Pan, Y., Sha, L., Guo, Y., Li, J., Zhang, X., 2006. Comprehensively Harnessing Measures to Control Soil , Water and Nutrients Loss in Slope Cultivated Land of Red Soil in Yunnan. J. Soil Water Conserv. 20, 17-21.

63. Montgomery, D.R., 2007. Soil erosion and agricultural sustainability. Proc. Natl. Acad. Sci. U. S. A. 104, 13268-72. https://doi.org/10.1073/pnas.0611508104 
780

781

782

783

784

785

786

787

788

789

790

791

792

793

794

795

796

797

798

799

800

801

802

803

804

805

806

807

808

809

810

811

812

813

814

815

816

817

818

819

820

821

822

64. Ng, S.L., Cai, Q.G., Ding, S.W., Chau, K.C., Qin, J., 2008. Effects of contour hedgerows on water and soil conservation, crop productivity and nutrient budget for slope farmland in the Three Gorges Region (TGR) of China. Agrofor. Syst. 74, 279-291. https://doi.org/10.1007/s10457-008-9158-x

65. Panagos, P., Ballabio, C., Borrelli, P., Meusburger, K., Klik, A., Rousseva, S., Tadić, M.P., Michaelides, S., Hrabalíková, M., Olsen, P., Aalto, J., Lakatos, M., Rymszewicz, A., Dumitrescu, A., Beguería, S., Alewell, C., 2015. Rainfall erosivity in Europe. Sci. Total Environ. 511, 801-814. https://doi.org/10.1016/j.scitotenv.2015.01.008

66. Prosdocimi, M., Tarolli, P., Cerdà, A., 2016. Mulching practices for reducing soil water erosion: A review. Earth-Science Rev. 161, 191-203. https://doi.org/10.1016/j.earscirev.2016.08.006

67. Qin, T., Jiang, X., Chen, Z., Xiang, M., 1996. Experiment of soil and water benefit of ridge plantation in different angle. Sichuan Water Resour. 17, 25-28.

68. Qin, W., Guo, Q., Zuo, C., Shan, Z., Ma, L., Sun, G., 2016. Spatial distribution and temporal trends of rainfall erosivity in mainland China for 1951-2010. Catena 147, 177-186. https://doi.org/10.1016/j.catena.2016.07.006

69. Quinton, J.N., Govers, G., Van Oost, K., Bardgett, R.D., 2010. The impact of agricultural soil erosion on biogeochemical cycling-s2. Nat. Geosci. 3, 1-6. https://doi.org/10.1038/ngeo838

70. Renard, K.G., Foster, G.R., Weesies, G.A., McCool, D.K., Yoder, D.C., 1997. Predicting soil erosion by water: a guide to conservation planning with the revised universal soil loss equation (RUSLE)., in: Agriculture Handbook (Washington). US Government Printing Office.

71. Rodríguez, O.S., 1997. Hedgerows and mulch as soil conservation measures evaluated under field simulated rainfall. Soil Technol. 11, 79-93. https://doi.org/10.1016/S0933-3630(96)00117-1

72. Rstudio Team, 2015. RStudio: Integrated Development Environment for R.

73. Ruan, F., 1995. Influence of inclination and length of slope on soil erosion in granite area of Fujian. J. Fujian Norm. Univ. (National Sci. 11, 100-106.

74. Schertz, D.L., 1983. The basis for soil loss tolerances. J. Soil Water Conserv. 38, 1014.

75. Shen, Z., Gong, Y., Li, Y., Liu, R., 2010. Analysis and modeling of soil conservation measures in the Three Gorges Reservoir Area in China. Catena 81, 104-112. https://doi.org/10.1016/j.catena.2010.01.009

76. Shi, H., Shao, M., 2000. Soil and water loss from the Loess Plateau in China. J. Arid Environ. 45, 9-20. https://doi.org/10.1006/jare.1999.0618

77. Shui, J., Ye, Y., Liu, C., 2002. Regularity of Erosion and Soil Loss Tolerance in Hilly Red-Earth Region of China. Agric. Sci. China 1, 1232-1237.

78. Smets, T., Poesen, J., Bochet, E., 2008. Impact of plot length on the effectiveness of different soil-surface covers in reducing runoff and soil loss by water. Prog. Phys. Geogr. 32, 654-677. https://doi.org/10.1177/0309133308101473

79. Stockmann, U., Minasny, B., McBratney, A.B., 2014. How fast does soil grow? Geoderma 216, 48-61. https://doi.org/10.1016/j.geoderma.2013.10.007 
80. Su, B., Liu, P., 2014. Characteristics of soil loss and runoff of runoff plot on Yizhe catchment. J. Green Sci. Technol. 4, 4-7.

81. Sun, H., Tang, Y., Chen, K., He, Y., 1999. Effect of contour hedgerow system on slope lands erosion control. Bull. Soil Water Conserv. 19, 1-5.

82. Sun, J., Yang, Y., Zhang, B., He, J., 1997. Hilly field erosion regulation in low mountain region of northern Liaoning. Res. Soil Water Conserv. 4, 65-74.

83. Tang, Q., Tian, Z., 2002. A Preliminary Report on the Study of Soil Conservation Technology of the New Exploited Orchard of Red Soil Sloping Fields. J. Guangxi Agric. 44-49.

84. Tang, Y., Dai, S., Jiang, G., Shi, D., Chen, Z., 2010. Calculation and Analysis of the Vegetation Cover and Management Factor C Value in Slope Farmland of Chongqing Area. J. Soil Water Conserv. 24, 53-59.

85. Tao, Y., Xiang, F., Ren, W., Lin, L., Chen, J., 2015. Effect of engineering measures on soil and water conservation on granite red soil slope. J. Soil Water Conserv. 29, 3439.

86. Taye, G., Poesen, J., Wesemael, B. Van, Vanmaercke, M., Teka, D., Deckers, J., Goosse, T., Maetens, W., Nyssen, J., Hallet, V., Haregeweyn, N., 2013. Effects of land use, slope gradient, and soil and water conservation structures on runoff and soil loss in semi-arid Northern Ethiopia. Phys. Geogr. 34, 236-259.

87. Tian, B., Chen, Q., Wang, K., 2006. Study on Runoff and Sedmient Production on Slopes Treated by Different Measures in Dry- hot Valley of Jinshajiang River. J. Southwest For. Coll. 26, 44-48.

88. Van Oost, K., Quine, T.A. a, Govers, G., De Gryze, S., Six, J., Harden, J.W., Ritchie, J.C., McCarty, G.W., Heckrath, G., Kosmas, C., Giraldez, J. V, da Silva, J.R.M., Merckx, R., 2007. The impact of agricultural soil erosion on the global carbon cycle. Science 318, 626-629. https://doi.org/10.1126/science.1145724

89. Wang, J.-J., Jiang, Z.-D., Xia, Z.-L., 2014. Grain-for-Green Policy and Its Achievements, in: Tsunekawa, A., Liu, G., Yamanaka, N., Du, S. (Eds.), Restoration and Development of the Degraded Loess Plateau, China SE - 10, Ecological Research Monographs. Springer Japan, pp. 137-147. https://doi.org/10.1007/978-4-43154481-4_10

90. Wang, J., Luo, S., Ye, D., 2008. Benefits of biological measures to the soil and water conservation in Gannan Mountain Area. Sci. Soil Water Conserv. 6, 37-43.

91. Wang, J., Yin, W., Liu, D., 2011. Influence of Intercropping Maize with Alfalfa on Runoff and Sediment Yield after Rainfall on Loess Slope Land. Water Sav. Irrig. 43$46,54$.

92. Wang, W., 2006. The Relationship Between Rainfall and Soil Erosion Under Different Land Uses in Slope Land of Northern Fujian. Res. Soil Water Conserv. 13, 134-136.

93. Wang, X., Gao, H., Tullberg, J.N., Li, H., D, N.K., McHugh, A.D., Li, and Y., 2008. Traffic and tillage effects on runoff and soil loss on the Loess.pdf. Aust. J. Soil Res. 46, 667-675.

94. Wang, X., Zhang, T., Zhang, B., 1998. No-tillage and cover on sloping cropland on the red soil region. Soils $2,84-88$. 
866

867

868

869

870

871

872

873

874

875

876

877

878

879

880

881

882

883

884

885

886

887

888

889

890

891

892

893

894

895

896

897

898

899

900

901

902

903

904

905

906

907

908

95. Wei, W., Chen, D., Wang, L., Daryanto, S., Chen, L., Yu, Y., Lu, Y., Sun, G., Feng, T., 2016. Global synthesis of the classifications, distributions, benefits and issues of terracing. Earth-Science Rev. 159, 388-403. https://doi.org/10.1016/j.earscirev.2016.06.010

96. Wu, F., Zhao, X., Liu, B., Jia, R., 1998. Influence of Cultivation Activities on the Runoff and Erosion on Slopeland. J. Northwest For. Coll. 13, 20-25.

97. Wu, J., Li, Y., 1998. Study on the relationship between different control measurement on runoff and sediment in a limestone watershed. Beijing Water 1316.

98. Xiang, D., Yong, T., Yang, W., Yu, X., Guo, K., 2010. Effects of planting system on soil and water conservation and crop output value in a sloping land of southwest China. Chinese J. Appl. Ecol. 21, 1461-1467.

99. Xiao, J., 2014. Satellite evidence for significant biophysical consequences of the "Grain for Green" Program on the Loess Plateau in China. J. Geophys. Res. Biogeosciences 119, 2261-2275. https://doi.org/10.1002/2014JG002820

100. Xie, S., Zeng, J., Yang, J., Yan, F., 2010. Effects of different tillage measures on soil and water conservation in slope farmland of red soil in Southern China. Trans. CSAE $26,81-86$.

101. Xie, T., Xie, S., Zhao, L., Yang, A., 2015. Experiment of planting effect on ridge hayrick field in sloping farmland of red soil and low hilly land. J. Water Resour. Water Eng. 26, 220-224.

102. Xiong, L., Zhao, Y., Gong, J., Long, J., Liu, Y., Zhang, D., Fu, H., 2007. Influence of the Cultivation-free Tea Gardens of Sloping Fields on Water and Soil Conservation and Soil Properties. TEA Commun. 34, 10-14.

103. Xiong, M., Sun, R., Chen, L., 2018. Effects of soil conservation techniques on water erosion control: A global analysis. Sci. Total Environ. 645, 753-760. https://doi.org/10.1016/j.scitotenv.2018.07.124

104. Xu, Q., Wang, T., Li, Z., Cai, C., Shi, Z., Jiang, C., 2010. Effect of soil conservation measurements on runoff, erosion and plant production : A case study on steeplands from the Three Gorges Area, China. J. Food, Agric. Environ. 8, 980-984.

105. Xue, Y., Li, Y., Wang, Z., Fan, M., 2011. Effect of Straw Mat Mulch on Soil \& Water Loss of Slope Arable Land and Seed Yield. Chinese Agric. Sci. Bull. 27, 192-198.

106. Yan, L., Hou, Q., Wang, F., Mu, X., 2013. Effectiveness of Soil and Water Conservation Practices in Runoff Control on Slope Lands in Loess Plateau. Bullet Soil Water Conserv. 33, 213-217.

107. Yang, J., Mo, M., Song, Y., Chen, X., 2012. Hydro-ecological effects of citrus land under vegetation measures of soil and water conservation in red-soil slope. Resour. Environ. Yangtze Basin 21, 994-999.

108. Yang, M.-Y., Tian, J.-L., Liu, P.-L., 2006. Investigating the spatial distribution of soil erosion and deposition in a small catchment on the Loess Plateau of China, using 137Cs. Soil Tillage Res. 87, 186-193. https://doi.org/10.1016/j.still.2005.03.010

109. Yin, D., Tang, H., Zhu, Q., Li, Y., Li, D., Liang, D., 2001. Research on Alley Cropping Technology Integrated Terracing Slope Land. J. Soil Water Conserv. 15, 84-87. 
909

910

911

912

913

914

915

916

917

918

919

920

921

922

923

924

925

926

927

928

929

930

931

932

933

934

935

936

937

938

939

940

941

942

943

944

945

946

947

948

949

950

951

952

110. You, Z., 2003. The Overland Flow in Different Soil Plough Measures of Dendrocalamus latiflorus Planted on Hilly Country. J. Fujian Coll. For. 23, 119-123.

111. Yu, D., Dai, Q., Wang, Q., Xiao, B., 2010. Effects of contour grass hedges on soil and water losses of sloping cropland in Beijing. Trans. CSAE 26, 89-96.

112. Yuan, D., Wang, Z., Chen, X., Guo, X., Zhang, R., 2001. Properties of Soil and Water Loss from Slope Field in Red Soil in Different Farming Systems. J. Soil Water Conserv. 15, 66-69.

113. Yue, H., 2008. Analysis on the Impacts and the Ecological Benefits of Different Conservation Measures to Vegetation Growth on the Serious Eroded Mountain Areas. Subtrop. Soil Water Conserv. 20, 23-27.

114. Zhang, J.H., Lobb, D.A., Li, Y., Liu, G.C., 2004. Assessment of tillage translocation and tillage erosion by hoeing on the steep land in hilly areas of Sichuan, China. Soil Tillage Res. 75, 99-107. https://doi.org/10.1016/j.still.2003.08.003

115. Zhang, P., Yan, L., Fan, J., Jiang, P., Wu, Y., Cai, L., Xu, H., Wang, X., Wu, S., 2011. Effects of Different Patterns of Contour Grass Hedgerow on Soil Erosion Control. J. Ecol. Rural Environ. 27, 29-34.

116. Zhang, S., Zhang, X., Liu, X., Liu, S., Yu, T., 2009. Tillage Effect on Soil Erosion in Typical Black Soil Region. J. Soil Water Conserv. 33, 11-15.

117. Zhang, X., Zhang, Y., Wen, A., Feng, M., 2003. Assessment of soil losses on cultivated land by using the 137 Cs technique in the Upper Yangtze River Basin of China. Soil Tillage Res. 69, 99-106. https://doi.org/10.1016/S0167-1987(02)00131-9

118. Zhao, J., Oost, K. Van, Chen, L., Govers, G., 2016a. Moderate topsoil erosion rates constrain the magnitude of the erosion-induced carbon sink and agricultural productivity losses on the Chinese Loess Plateau. Biogeosciences 13, 4735-4750. https://doi.org/10.5194/bg-13-4735-2016

119. Zhao, J., Vanmaercke, M., Chen, L., Govers, G., 2016b. Vegetation cover and topography rather than human disturbance control gully density and sediment production on the Chinese Loess Plateau. Geomorphology 274, 92-105. https://doi.org/10.1016/j.geomorph.2016.09.022

120. Zhao, T., Xie, Y., Jiang, Q., Zhang, H., Zhou, W., 2011. Traditional control measures of soil erosion and their environmental effects on flow and sediment in the water source area of Beijing and Tianjin. Sci. Soil Water Conserv. 9, 32-37.

121. Zhao, Y., Wei, Y., 2009. Soil and water conservation effects of protective tillage measures on sloping farmland. Sci. Soil Water Conserv. 7, 86-90.

122. Zheng, H., Fang, S., Yang, J., Zhang, H., Wang, B., Mo, M., 2012. Reduction effects of three garden types on runoff, sediment and nutrient loss in the red soil hilly region of China. J. Food, Agric. Environ. 3\&4, 1301-1307.

123. Zhou, J., 2007. Basic Benefits from Soil and Water Conservation in Sanchahe Small Watershed. Bullet soil Water Conserv. 27, 63-64, 74.

124. Zhou, Y., Wei, T., Xie, J., Shi, X., Ge, G., Dong, Z., Cheng, Z., 2011. Different Types of Vegetation Cover and Water Conservation Benefits. J. Soil Water Conserv. 25, $12-21$.

125. Zi, S., Duan, Q., Wu, B., 2006. Effects of mixed grass strip on reducing water and soil losses in sloping fields. Trans. CSAE 22, 61-65. 
953 